\title{
DINÂMICA DE POPULAÇÕES EM AUTÔMATOS CELULARES
}

\section{Giovano de Oliveira Cardozo}

Orientador: Prof. Dr. José Fernando Fontanari

Tese apresentada ao Instituto de Física de São Carlos, Universidade de São Paulo, para a obtenção do título de Doutor em Física, Área de Concentração: Física Básica.

\section{SÃO CARLOS}

São Paulo - Brasil

Setembro - 2006 
Para Diana e Giovana 


\section{AGRADECIMENTOS}

Agradeço em primeiro lugar à FAPESP, pelo suporte material sem o qual o desenvolvimento do trabalho seria impossível, a minha família, pela compreensão das minhas necessidades durante a realização do trabalho, Fontanari, pela confiança depositada em mim durante todo esse tempo, mesmo quando eu nem sempre correspondi às expectativas iniciais, e principalmente pela oportunidade de trabalho e crescimento enquanto pesquisador, Cris, por toda a parte burocrática dos meus relatórios e pelo suporte sempre presente nas horas complicadas, Daniel, por sua amizade, nossos "altos papos", a revisão nesta tese e a oportunidade de colaboração, Colato, pela amizade dos últimos quatro anos, pelo pingue-pongue, as "pizzas", o Tênis das tardes e a oportunidade de colaboração, Leo, pelo exemplo de determinação e competência, pelo pingue-pongue, a amizade dos últimos anos e pela presença constante nos momentos mais importantes, Petrus pelos churrascos sempre tão agradáveis, Fabio, Paulo Castro, Guilherme, Paulo Campos e Viviane, Alexandre Rosas, Antonio Seridonio, Antonio Francisco, professor Jabá, professor Richard, Jô, secretária do DF da UFSCar, pessoal da informática, pessoal da biblioteca, pessoal do RU e todos aqueles que contribuíram direta ou indiretamente para a realização deste trabalho. 


\section{SUMÁRIO}

Página

LISTA DE FIGURAS vi v

LISTA DE TABELAS $\quad x$

RESUMO Xi xi

SUMMARY xii

1 INTRODUÇÃO 1

1.1 Transições de Fase Longe do Equilíbrio . . . . . . . . . . . . . . . . . . . 5

1.1.1 Modelo Replicador-Enzima . . . . . . . . . . . . . . . . . . 6

1.1.2 Modelo bidimensional de Criação por Pares e Trincas . . . . . . . . . . 7

1.1.3 Modelo difusivo de Criação por Trincas . . . . . . . . . . . . . . . . 8

1.2 Gerando Números Primos . . . . . . . . . . . . . . . . . . 9

2 PERCOLAÇÃO DIRIGIDA 10

2.1 Introdução . . . . . . . . . . . . . . . . . . . . . 10

2.2 Processo difusivo . . . . . . . . . . . . . . . . . . . . . . . . 11

2.2.1 Da difusão isotrópica à Percolação Dirigida . . . . . . . . . . . . . . 11

2.2.2 Percolação Dirigida: um Processo Dinâmico . . . . . . . . . . . . . . . 14

2.3 Modelos de Rede para Percolação Dirigida . . . . . . . . . . . . . . . . . 17

2.3.1 Autômato Celular de Domany-Kinzel . . . . . . . . . . . . . . . . 17

2.3.2 O Processo de Contato . . . . . . . . . . . . . . . . . . . . 19

2.3.3 O processo de contato conservativo . . . . . . . . . . . . . . . 21 
2.3.4 O modelo Ziff-Gulari-Barshad para catalise heterogênea . . . . . . . . 22

2.4 Leis de Escala . . . . . . . . . . . . . . . . . . . . . . . . . . 25

2.4.1 Os expoentes críticos $\beta, \nu_{\perp}, \nu_{\|}, \delta, \eta$ e $z \ldots \ldots \ldots \ldots$

2.4.2 Percolação Dirigida Compacta . . . . . . . . . . . . . . . . . . . . . . . 29

3 MODELO REPLICADOR-ENZIMA 31

3.1 Introdução . . . . . . . . . . . . . . . . . . . . . . . 31

3.2 Simulações e resultados . . . . . . . . . . . . . . . . . . . . . . . 34

3.3 Conclusão . . . . . . . . . . . . . . . . . . . . . . . . . . . 39

4 CRIAÇÃO POR PARES E TRINCAS 41

4.1 Introdução . . . . . . . . . . . . . . . . . . . . . 41

4.2 Simulações e resultados . . . . . . . . . . . . . . . . . . . . . . . . . 42

4.3 Conclusão . . . . . . . . . . . . . . . . . . . . . . 50

5 CRIAÇÃO POR TRINCAS

5.1 Análise de Espalhamento . . . . . . . . . . . . . . . . . . . 54

5.2 Processo de Contato Conservativo Difusivo . . . . . . . . . . . . . . 56

5.3 Conclusão . . . . . . . . . . . . . . . . . . . . . . . 59

6 OS NÚMEROS PRIMOS E A COMPETIÇÃO 60

6.1 Introdução . . . . . . . . . . . . . . . . . . . . . . . . . 60

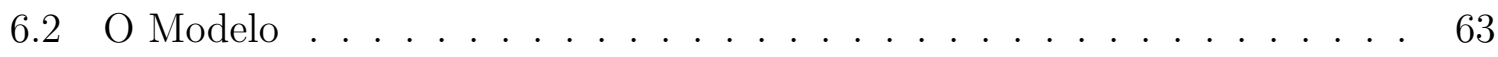

6.3 Resultados . . . . . . . . . . . . . . . . . . . 64

6.4 Conclusão . . . . . . . . . . . . . . . . . . . . . 70

7 CONCLUSÕES GERAIS $\quad 71$ 


\section{LISTA DE FIGURAS}

Página

1 Rede linear e aplicação das condições de contorno periódicas. . . . . . . . . . . . . . 4

2 Condições de contorno periodicas toroidais. . . . . . . . . . . . . . . . . . 5

3 Percolação Ordinária e Dirigida numa rede quadrada diagonal com condições de contorno livres. . . . . . . . . . . . . . . . . . . . . . . . . . . 12

4 Percolação Dirigida em 1+1 dimensões interpretada como um processo estocástico dependente do tempo. Ligações abertas são indicadas pelas linhas cheias e os sítios ativos pelos círculos preenchidos. A regra de atualização deste sistema é dada pela

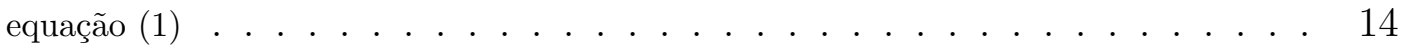

5 Percolação Dirigida em 1+1 dimensões com condições iniciais aleatórias (acima) e com semente ativa (abaixo) . . . . . . . . . . . . . . . . . . . 16

6 Probabilidades de atualização no autômato celular (1+1)-dimensional de Domany-Kinzel 18

$7 \quad$ Diagrama de fases do modelo de Domani-Kinzel . . . . . . . . . . . . . . . . . . 19

8 Processo estocástico no processo de contato $(1+1)$-dimensional. Sítios infectados (círculos cheios) contaminam seus vizinhos à uma taxa $\lambda / 2$ e se recuperam à uma taxa 1. A parte superior mostra as regras de atualização de acordo com a equação (6). A parte inferior mostra uma definição equivalente ao processo de dois sítios . . . . . . 21

9 Esquema da reação de oxidação do monóxido de carbono em superfície de platina. . . 23

10 Diagrama de fases esquemático do modelo ZGB. A linha cheia representa a concentração de oxigênio e a linha pontilhada a concentração de monóxido de carbono. . . 24

11 Densidade estacionária $\rho^{\text {stat }}$ na fase ativa para Percolação Dirigida em $1+1$ (quadrados) e $2+1$ (triângulos) dimensões, em escala linear (esquerda) e log-log. . . . . . . 26 
12 Interpretação geométrica dos comprimentos de correlação $\xi_{\|}$e $\xi_{\perp}$. . . . . . . . . . 27

13 Processos de Morte (à esquerda) e de Replicação . . . . . . . . . . . . . . . . . . 33

14 Processos de Produção da enzima (à esquerda) e Catálise . . . . . . . . . . . . . . 33

15 Processo de Não Ocupação . . . . . . . . . . . . . . . . . . . . . . . . . . . . 33

$16 \Pi$ contra $s_{1}$ e $\Pi$ contra $\Delta-c_{1}=s_{p}=0.00 \ldots \ldots \ldots \ldots \ldots$

$17 \Pi$ contra $s_{1}$ e $\Pi$ contra $\Delta-c_{1}=0.01$ e $\alpha=2.00 \ldots \ldots$. . . . . . . . . . 36

$18 \Pi$ contra $s_{1}$ e $\Pi$ contra $\Delta-c_{1}=0.05$ e $\alpha=1.00 \ldots \ldots$. . . . . . . . 36

$19 \Pi$ contra $s_{1}$ e $\Pi$ contra $\Delta-c_{1}=0.05$ e $\alpha=2.00 \ldots \ldots$. . . . . . . . . 37

20 Diagrama de fases $s_{1}^{*}$ x $\alpha \ldots \ldots \ldots$. . . . . . . . . . . . . . . . . . . . . .

$21 \quad$ Diagrama de fases $s_{1}^{*}$ x $c_{1} \ldots \ldots \ldots \ldots \ldots$

22 Ilustração das regras de ocupação de um sítio vazio $(2,3)$ pelo replicador $(2,2)$. Uma cópia do replicador ocupa aquele sítio com probabilidade $s \in(0,1]$ se há ao menos $K$ replicadores na soma de $(1,2),(2,1)$ e $(3,2) \ldots \ldots$. . . . . . . . . . . . 42

23 Curvas de $N(t)$ e $P(t)$, no processo de contato ordinário, para $k=0$ e $s=0.1$, com $\gamma=0.239,0.2391,0.23918,0.2392$ e 0.2394 (de cima para baixo). Com esses dados obtivemos $\eta=0.241$ e $\delta=0.455 \ldots \ldots \ldots \ldots$. . . . . . . . . . . 44

24 Curvas de $R^{2}(t)$, no processo de contato ordinário, para $k=0$ e $s=0.1$, com $\gamma=0.239,0.2391,0.23918,0.2392$ e 0.2394 (de cima para baixo). Com esses dados obtivemos $z=1.128$. À esquerda em escala linear podemos diferenciar as curvas, o que já não é possível na escala log-log. . . . . . . . . . . . . . . . . . . . . . . 44

25 Curvas de $N(t)$, no processo de contato ordinário, para $k=0$ e $s=0.1$, com $\gamma$ entre 0.241 e 0.255 , no intervalo subcrítico (à esquerda) e o gráfico de $-\lambda=-\xi_{\|}$em função da distância em relação ao crítico. Com esses dados obtivemos $\nu_{\|}=1.273 . \quad$. . . . .

26 Curvas do processo de contato conservativo para $k=0$. À esquerda o gráfico de $\rho$ contra $\gamma$ para $s=0.1,0.2,0.3$ e 0.4 da esquerda para a direita. À direita o gráfico de $\rho$ contra $\Delta_{0}=\gamma^{*}-\gamma$ para $s=0.1$. Do segundo gráfico obtivemos $\beta=0.587$. . . .

27 Curvas de $N(t)$ e $P(t)$, no processo de contato ordinário, para $k=1$ e $s=0.1$, com $\gamma=0.1574,0.1575,0.15756,0.1576,0.1577$ e 0.1579 (de cima para baixo). Com esses dados obtivemos $\eta=0.23$ e $\delta=0.47 \ldots \ldots \ldots \ldots$ 
28 Curvas de $R^{2}(t)$, no processo de contato ordinário, para $k=1$ e $s=0.1$, com $\gamma=$ $0.1574,0.1575,0.15758,0.1576,0.1577$ e 0.1579 (de cima para baixo). Com esses dados obtivemos $z=1.144 \ldots \ldots \ldots \ldots \ldots$

29 Curvas de $N(t)$, no processo de contato ordinário, para $k=1$ e $s=0.1$, com $\gamma$ entre 0.148 e 0.173 , no regime subcrítico (à esquerda) e o gráfico de $-\lambda=-\xi_{\|}$em função da distância em relação ao crítico. Com esses dados obtivemos $\nu_{\|}=1.215$. . . . .

30 Curvas do processo de contato conservativo para $k=1$. À esquerda o gráfico de $\rho$ contra $\gamma$ para $s=0.1,0.2,0.3,0.4$ e 0.5 da esquerda para a direita. À direita o gráfico de $\rho$ contra $\Delta_{1}$ para $s=0.1$. Do segundo gráfico obtivemos $\beta=0.57$. . . . . .

31 Curvas de $N(t)$ e $P(t)$, no processo de contato ordinário, para $k=2$ e $s=0.1$, com $\gamma=0.0725,0.0726,0.072645,0.0727$ e 0.0728 (de cima para baixo). Com esses dados obtivemos $\eta=0.0$ e $\delta=1.01 \ldots \ldots \ldots \ldots \ldots \ldots$

32 Curvas do processo de contato conservativo para $k=2$. À esquerda o gráfico de $\rho$ contra $\gamma$ para $s=0.1,0.2,0.3,0.4,0.5$ e 1.0 da esquerda para a direita.A linha pontilhada é uma lei de potência com expoente 0.41. À direita o gráfico de $\rho$ contra $\gamma$ para $s=0.1$ e $L=201,101,51,21,11,7$ e 5 . Na inserção uma comparação dos dados obtidos no processo de contato ordinário (linha segmentada) com os obtidos pelo processo de contato conservativo com $L=11$ (linha cheia). . . . . . . . .

33 Análise de espalhamento para $K=2, s=0.1$ na região super crítica. Esquerda: gráfico $\log$-log de $P(t)$ evidenciando os valores de saturação $P_{\infty}$. Os valores de $\gamma$ são $0.06,0.07,0.072,0.0723,0.07244,0.07250,0.07258$ e 0.07259 de cima para baixo. Direita: gráfico $\log -\log$ de $P_{\infty}\left(\gamma-\gamma^{*}\right)$. A inclinação da linha cheia é $\beta^{\prime}=1.16 \pm 0.09$.

34 Análise de espalhamento para $K=2, s=0.1$ na região sub crítica. Esquerda: gráfico monolog de $N(t)$. A inclinação de cada linha representa o expoente $1 / \xi_{\|}$do decaimento exponencial da população neste regime. Os valores de $\gamma$ variam entre 0.074 e 0.0728 com passo -0.0001 da esquerda para a direita. Direita: gráfico $\log -\log$ de $1 / \xi_{\|}$em função de $\left|\gamma-\gamma^{*}\right|$. A inclinação da linha cheia é $\nu_{\|}=1.1 \pm 0.1 \ldots$. . . . . . . 
35 Análise de espalhamento para $K=2, s=0.1,0.3,0.4,0.5$ e 1 de baixo para cima. Esquerda: gráfico log-log de $N(t)$. Direita: gráfico log-log de $P(t)$. A mudança nas inclinações indicam alteração no comportamento crítico. Neste caso a transição muda

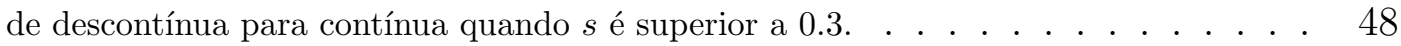

36 Comparação entre os valores críticos de $\gamma$ em função de s para $k=0,1$ e 2. . . . . 50

37 Análise de espalhamento com $D=0$. O valor crítico de $\lambda$ é 12.015 e os valores dos expoentes críticos $\eta, \delta$ e $z$ são $0.316,0.160$ e 1.27 respectivamente. . . . . . . . . . 55

38 Análise de espalhamento com $D=0.95$. Valor crítico de $\lambda$ é 10.11 e os expoentes críticos $\eta, \delta$ e $z$ iguais a $0.24,0.25$ e 1.15 respectivamente. . . . . . . . . . . 55

39 Análise de espalhamento com $D=0.98$. Valor crítico de $\lambda$ é 9.6 e os expoentes críticos $\eta, \delta$ e $z$ iguais a $-0.003,0.5$ e 1.09 respectivamente. . . . . . . . . . . 56

40 Processo de contato conservativo, com $D=0$. À esquerda curvas de $\rho$ em função de $\alpha^{\prime}$, com $L=100,200$ e 10000 da mais externa para a mais interna. À direita gráfico $\log$-log de $\rho$ contra $\Delta=\gamma-\gamma^{*}$, onde $\gamma^{*}=0.0768$. O expoente crítico $\beta$ foi estimado

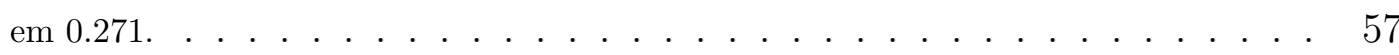

41 Processo de contato conservativo, com $D=0.95$. À esquerda curvas de $\rho$ em função de $\alpha^{\prime}$, com $L=100,200$ e 10000 da mais externa para a mais interna.À direita gráfico $\log -\log$ de $\rho$ contra $\Delta$, onde $\gamma^{*}=0.00449$. O expoente crítico $\beta$ foi estimado em 0.251. 57

42 Processo de contato conservativo, com $D=0.98$. À esquerda curvas de $\rho$ em função de $\alpha^{\prime}$, com $L=100,200$, e 10000 da mais externa para a mais interna. À direita gráfico log-log de $\rho$ contra $\Delta$, onde $\gamma^{*}=0.00189$. . . . . . . . . . . . . . . . . 58

$43 P_{\infty}$ em função de $\Delta$ para $D=0.0,0.95$ e 0.98 . Os expoentes $\beta^{\prime}$ associados são: $0.282(6)$ para $D=0.0,0.65(1)$ para $D=0.95$ e $0.98(5)$ para $D=0.98 \ldots \ldots \ldots$

44 Resultados para $k=2, x_{0}=0.1$ e $\mu=0 \ldots \ldots \ldots$. . . . . . . . 66

45 Resultados para $k=2, x_{0}=0.1$ e $\mu=10^{-3} \ldots \ldots \ldots$. . . . . . . . . . . 67

46 Resultados para $k=2, x_{0}=0.5$ e $\mu=0 \ldots \ldots \ldots$. . . . . . . . . 67

47 Resultados para $k=3, x_{0}=0.5$ e $\mu=0 \ldots \ldots \ldots$. . . . . . . . . 68

48 Resultados para $k=4, x_{0}=0.5$ e $\mu=0 \ldots \ldots \ldots$. . . . . . . . . 68 


\section{LISTA DE TABELAS}

Página

1 Expoentes críticos em função da dimensão do sistma. . . . . . . . . . . . . . . . . . 29

2 Expoentes críticos da Percolação Dirigida Compacta. [1] . . . . . . . . . . . . . . 30

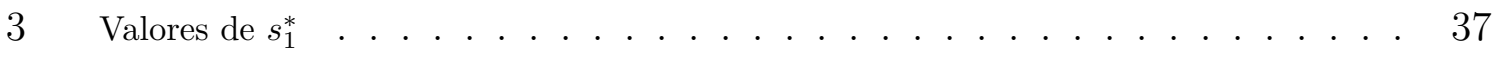

$4 \quad$ Valores de $\beta^{\prime}$ nos pontos críticos . . . . . . . . . . . . . . . . . . . . 37 


\section{DINÂMICA DE POPULAÇÕES EM AUTÔMATOS CELULARES}

\section{RESUMO}

O estudo da dinâmica de populações vem adquirindo grande importância atualmente, por suas aplicações nas mais diversas áreas do conhecimento, como a biologia evolutiva, ecologia, economia e computação, entre outras. O uso de redes, ou autômatos celulares, para modelar dinâmicas populacionais é um recurso frequentemente utilizado por sua simplicidade no tratamento de problemas com alto grau de complexidade. Neste trabalho utilizamos autômatos celulares para simular dinâmicas populacionais onde analisamos transições de fases longe do equilíbrio em modelos de replicação em uma e duas dimensões, classificando-as de acordo com suas classes de universalidade. Também utilizamos redes para estudar as possíveis origens dos ciclos primos presentes nas cigarras do gênero Magicicada que habitam a América do Norte, mostrando que a predação não é necessária para o surgimento deste comportamento. 


\section{CELLULAR AUTOMATA POPULATION DYNAMICS}

\section{SUMMARY}

The study of population dynamics becomes even more important nowadays because of its applications in a wide range of subjects, such as evolutive biology, ecology, economics and computational sciences, among many others. The use of networks, as well as cellular automata, to simulate populational dynamics is an ordinary tool because of its simplicity in the treatement of very complicated problems. In this work we use cellular automata to simulate populational dynamics where non equilibrium phase transitions in replicator models in one and two dimensions are analyzed and characterized by their universality classes. We also use cellular automata to study the possible origins of prime number cycling present in northern american Magicicada, showing that it is possible to generate prime number year life cycles whithout any predation effects. 


\section{INTRODUÇÃO}

$\mathrm{Na}$ atualidade tem sido de grande interesse o estudo dos sistemas biológicos, em especial aqueles que simulam o processo evolutivo em qualquer nível, ou uma dinâmica populacional. Para o estudo de tais sistemas frequentemente nos utilizamos de modelos computacionais probabilísticos, como os autômatos celulares, que através de uma dinâmica local simples conseguem reproduzir comportamentos complexos como aqueles presentes nos sistemas biológicos.

O autômato celular é uma idealização matemática de um sistema físico onde tempo e espaço são variáveis discretas, e as proriedades físicas são

descritas por um conjunto de valores finito e discreto. É construído como uma rede regular geralmente infinita, podendo ser finita com o uso de condições apropriadas de contorno, composta por sítios dentro dos quais variáveis discretas descrevem seus estados individuais. O estado do autômato é completamente descrito pela conjunção dos estados individuais dos sítios e a evolução desses estados ocorre sempre em passos discretos de tempo onde o estado de cada sítio no tempo seguinte é influenciado pelo seu estado e de seus vizinhos no tempo atual e depende de regras locais. A atualização dos estados de cada sítio pode ser simultânea ou não. A definição da vizinhança de um sítio pode ser feita de muitas formas, sendo que a mais natural é a escolha dos sítios adjacentes. Uma explicação mais detalhada sobre a estrutura e a dinâmica dos autômatos é apresentada adiante.

Historicamente os autômatos celulares foram criados pelo matemático alemão Stanislaw Ulam (1909-1984) [2], que estava interessado em estudar a 
evolução de construções geométricas geradas por regras locais simples. A base da construção de Ulam era um espaço bidimensional dividido em células que podiam estar em um de dois estados, ligado ou desligado. Uma vez dada a condição inicial, o sistema evoluia baseado em regras de vizinhança, ou seja, o estado de cada sítio em determinado instante dependia do estado dele e de sua vizinhança no instante anterior. Ulam notou que esse mecanismo criava estruturas complexas e às vezes auto-similares. Dessa forma uma questão importante veio à tona: tal mecanismo recursivo simples poderia ser utilizado para explicar a complexidade de sistemas reais?

Com esse pensamento o matemático húngaro John von Neumann (1903-1957) [3], inspirado pelas idéias do matemático inglês Alan Turing (19121954) [4], começou a estudar os sistemas auto-replicantes com o objetivo de desenhar um modelo geral, capaz de reproduzir qualquer mecanismo auto-reprodutivo. Aconselhado pelo próprio Ulam a utilizar o que fora denominado espaço celular, para estruturar o mecanismo auto replicante, von Neumann conseguiu contornar as limitações impostas pela física na construção de um universo extremamente simples e ao mesmo tempo capaz de gerar estruturas de grande complexidade. Tal modelo foi batizado Autômato Celular.

Qualquer sistema físico composto por elementos discretos com interações locais pode ser tratado como um autômato celular. Desse modo, podemos encontrar uma grande variedade de exemplos de uso dos autômatos celulares, como redes cristalinas em um sólido, onde cada sítio traz o valor de alguma variável quantizada. Um sítio pode representar o estado de um certo conjunto de moléculas interagentes durante uma reação química. O conjunto de um certo número de sítios pode representar uma estrutura genômica de um indivíduo que interage com outros de modo que seja simulada uma dinâmica de evolução genética. O sítio pode representar um indivíduo em uma dinâmica social, como em um ecossistema ou 
como na dinâmica de mercados [5].

O surgimento de organização a partir de condições aleatórias num autômato faz dele um objeto muito útil para o estudo da evolução pré-biótica, uma vez que partindo de um estado inicial completamente desordenado estruturas complexas auto-reprodutivas emergem como resultado de dinâmicas locais.

Em uma dimensão um autômato celular pode ser representado por uma rede linear. A vizinhança natural de cada sítio, neste caso, é composta pelo sítio imediatamente anterior e o imediatemente posterior. A simulação de um autômato infinito consiste, na verdade, na utilização de um autômato finito, tão grande quanto se queira, de modo que em todo o tempo de simulação nunca haja participação de um sítio situato em uma de suas extremidades em alguma etapa da dinâmica. Em caso de um autômato finito de comprimento $N$, podemos aplicar a ele condições de contorno periódicas circulares, de modo que o vizinho anterior do primeiro sítio seja o último e o vizinho posterior do último seja o primeiro, construíndo uma rede em forma de anel, como pode ser visto na Figura 1.

No caso de uma rede retangular como representação de um autômato celular bidimensional, consideramos um conjunto de sítios distribuídos regularmente sobre um plano retangular de dimensões lineares $L$ e $M$. O número total de sítios $N$ é igual ao produto de $L$ por $M$. Essa construção é conhecida como rede retangular (ou quadrada no caso em que $N=M$ ) e a vizinhança de cada sítio pode ser construída de diversas formas. A mais comum é aquela onde os vizinhos mais próximos, nas direções dos pontos cardeais, compõem a vizinhança. Essa forma é chamada Vizinhança de von Neumann. Outra forma, chamda vizinhança de Moore, é constituída pelos oito sítios mais próximos, na forma de uma moldura quadrada que contorna o sítio em foco. 


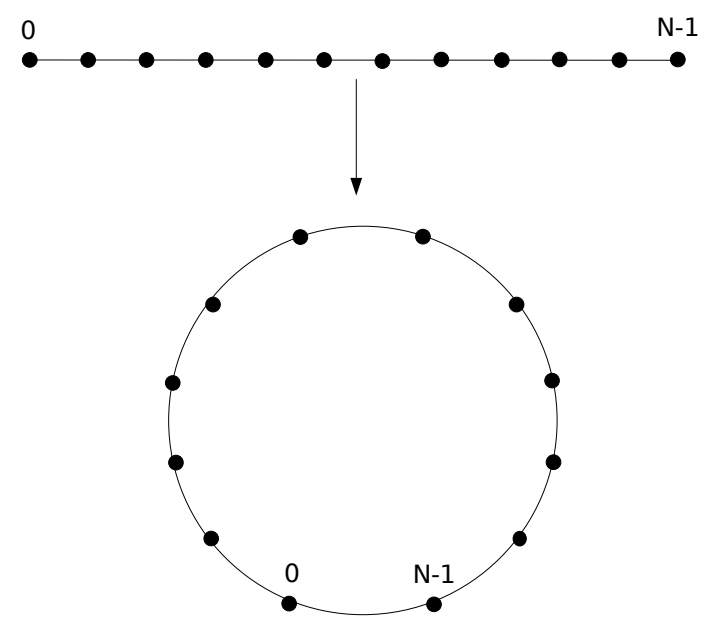

Figura 1: Rede linear e aplicação das condições de contorno periódicas.

O autômato bidimensional infinito, assim como no caso unidimensional, é uma rede com $L$ e $M$ escolhidos de forma que durante todo o tempo de execução nenhum sítio localizado nas bordas da rede participe da dinâmica. No caso dos autômatos finitos existem diversas formas de aplicar condições de contorno periódicas, sendo a mais comum a toroidal, onde as extremidades paralelas se conectam como vizinhas, conforme pode ser visto na sequência da Figura 2.

Neste trabalho utilizamos autômatos celulares para simular modelos auto-catalíticos onde existem transições de fase para estados absorventes, classificando essas transições de acordo com sua classe de universalidade através da análise dos expoentes críticos associados. Também utilizamos autômatos para modelar uma população de agentes cíclicos inspirados no comportamento das cigarras do gênero Magicicada da América do Norte, mostrando que em um ambiente essencialmente competitivo com estrutura espacial há o surgimento de ciclos primos como estratégias vencedoras na população. 

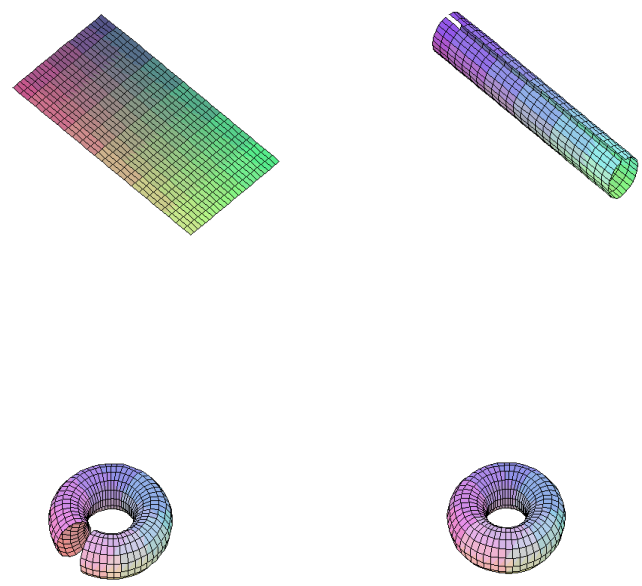

Figura 2: Condições de contorno periodicas toroidais.

\subsection{Transições de Fase Longe do Equilíbrio}

Atualmente existe uma teoria bem estabelecida para transições de fase em sistemas no equilíbrio, onde todos os expoentes críticos são bem conhecidos. Nos sistemas longe do equilíbrio também há transições de fase, e assim como no caso dos sistemas em equilíbrio essas transições estão relacionadas a expoentes críticos. No entanto uma teoria completa sobre as transições de fase longe do equilíbrio ainda não existe. A partir do cálculo dos expoentes críticos associados tem sido possível classificar as transições de fase de acordo com classes de universalidade (que são classes onde todas as transições apresentam o mesmo conjunto de expoentes críticos).

Pela conjectura de Janssen [6] e Grassberger [7], que fora generalizada posteriormente por Grinstein, Lai e Browne [8], modelos que apresentam transições contínuas para algum estado absorvente que seja único em cada sistema, possuem comportamento crítico pertencente à classe de universalidade da Percolação Dirigida. Essa conjectura é amplamente evidenciada e tem sido útil na determinação 
das propriedades críticas de uma diversidade de modelos.Aqui estudamos três modelos distintos onde há transições de fase para estados absorventes, classificando essas transições de acordo com sua classe de universalidade.

\subsubsection{Modelo Replicador-Enzima}

Neste modelo consideramos um autômato bidimensional finito dentro do qual convivem duas espécies de indivíduos, os replicadores e as enzimas. Os replicadores podem ser produzidos em sítios vazios através de dois processos, a replicação, onde um replicador localizado na vizinhança de von Neumann de um sítio vazio $i$, por exemplo, tem uma probabilidade dependente de um parâmetro $s_{1}$ de se replicar em $i$; e a replicação assistida, ou catalise, onde um replicador localizado na vizinhança de von Neumann de $i$ auxiliado por uma enzima localizada simultaneamente na vizinhança de Moore de $i$ e na vizinhança de von Neumann do replicador, tem uma probabilidade dependente de um parâmetro $c_{1}$ de se replicar para $i$. Um replicador que esteja na vizinhança de von Neumann de $i$ ainda tem uma probabilidade relacionada ao parâmetro $s_{p}$ de produzir uma enzima naquele sítio, sendo esse o único processo possível de criação de enzimas. Tanto enzimas quanto replicadores podem decair com probabilidade $\gamma$.

Pelas regras de reprodução notamos que o sistema apresenta um estado absorvente, composto por um conjunto de sítios completamente vazio, uma vez que sem a presença de replicadores é impossível criar novos replicadores ou enzimas. Dependendo das taxas escolhidas o sistema pode cair rapidamente no estado absorvente ou atingir um estado meta estável, o que determina a existência de uma transição de fase entre o estado meta estável e o estado absorvente. De acordo com os cálculos essa transição aparenta ser contínua e portanto pertencente a classe de universalidade da Percolação Dirigida.

O modelo é completamente descrito no capítulo 3. 


\subsubsection{Modelo bidimensional de Criação por Pares e Trincas}

Neste modelo, baseado em um autômato bidimensional, consideramos apenas uma espécie que se reproduz por replicação direta, onde apenas um replicador é necessário, ou por replicação assistida onde o replicador precisa de $k$ outros replicadores em sua vizinhança de von Neumann para replicar em um sítio vazio, que também esteja na mesma vizinhança, com probabilidade $1-(1-s)^{n_{0}}$, onde $n_{0}$ é o número de replicadores que possuem $k$ vizinhos e que estejam na vizinhança de von Neumann do sítio vazio para onde podem replicar, e $s$ é a probabilidade individual de replicação. Os replicadores também podem decair com probabilidade $\gamma$. Quando $k=0$ obtemos o processo de replicação direta. Quando $k=1$ obtemos o processo de criação por pares, e quando $k=2$ obtemos o processo de criação por trincas. O modelo é uma extensão bidimensional do modelo de criação por pares e trincas apresentado por Dickman e Tomé [9], que é unidimensional.

O modelo apresenta um estado absorvente, onde todos os sítios estão vazios, e uma transição de fase para esse estado. Através da análise de espalhamento do sistema e de estudos envolvendo o processo de contato conservativo introduzido por Tomé e Oliveira [10] (que é explicado com mais detalhes na seção 2.3.3) mostramos que a transição de fase, no caso de replicação simples e de criação por pares, é contínua e pertencente à classe de universalidade da Percolação Dirigida. Por outro lado, no caso da criação por trincas encontramos uma transição descontínua para baixos valores de $s$, mas que passa a contínua com o aumento do valor do parâmetro.

A descrição completa do modelo e de sua análise é apresentada no capítulo 4. Os resultados foram publicados na revista Physica A 359 (2006) 478-494. [11] 


\subsubsection{Modelo difusivo de Criação por Trincas}

Neste modelo exploramos um autômato unidimensional onde existe uma única espécie de replicador que se reproduz somente por trincas, ou seja, um replicador só pode ser criado em um sítio vazio que possua em sua vizinhança imediata uma trinca de replicadores vizinhos entre si. Diferentemente dos outros modelos aqui apresentados, neste um replicador pode difundir para um de seus sítios vizinhos que esteja vazio com probabilidade $D$. A replicação acontece com probabilidade $(1-D) \lambda /(1+\lambda)$. Um replicador pode decair com probabilidade $(1-D) /(1+\lambda)$.

O sistema apresenta um estado absorvente correspondente à rede totalmente vazia e consequentemente uma transição de fase para tal estado. O tipo de transição se mostrou dependente da intensidade de difusão. Com $D$ relativamente baixo os expoentes críticos obtidos, característicos dos processos de Percolação Dirigida, indicam uma transição contínua, ao passo que para alto grau de difusão, com $D$ próximo de 1 , a transição se torna descontínua. Neste caso a descontinuidade da transição é atestada pela presença de comportamentos críticos característicos de uma classe de universalidade chamada Percolação Dirigida Compacta, que é mencionada na seção 2.4.2. O estudo do processo de contato conservativo também foi aplicado ao modelo, com uma pequena adaptação referente ao seu caráter difusivo. Os resultados concordam com aqueles obtidos na análise de espalhamento.

O modelo difusivo de criação por trincas, portanto, apresenta uma migração em seu comportamento crítico da classe de universalidade da Percolação Dirigida para a Percolação Dirigida Compacta. Sua descrição detalhada é apresentada no capítulo 5 e seus resultados foram publicados na revista European Physical Journal B 51-4 (junho de 2006), 555-561. [12] 


\subsection{Gerando Números Primos}

Um fenômeno natural intrigante é a emergência de ciclos de vida longos e sincronizados em populações sobretudo de insetos. Entre os insetos que possuem tais estratégias de sobrevivência, um se destaca por adotar ciclos de vida com duração de 13 e 17 anos. Este inseto é a cigarra do gênero Magicicada, que existe na América do Norte e na Austrália. Seu ciclo é com certeza o mais longo entre todos os insetos, mas o que chama mais a atenção da comunidade científica é que a duração dos ciclos é de números primos de anos. A origem de tais ciclos ainda é um mistério, mas algumas hipóteses já vêm sendo consideradas desde o início do século XX.

Inspirados por diversos estudos teóricos e experimentais [13-19], Paulo Campos et al [20], propõem um modelo simples, baseado em um autômato celular bidimensional, que a origem dos ciclos primos teria relação com uma dinâmica de predação entre as cigarras e eventuais parasitas e aves. Porém, a partir de uma proposição feita por Grant [21] de que a origem dos ciclos primos não seria relacionada com a predação, mas com a competição [22-27], reescrevemos o modelo de modo que nele não houvesse predação e com isso mostramos, através de um autômato celular semelhante ao de Campos, que a predação não é necessária para o surgimento dos ciclos primos, bastanto um ambiente competitivo, espacialmente estruturado, para tanto. 


\title{
2 PERCOLAÇÃO DIRIGIDA
}

\author{
UMA REVISÃO SOBRE O ASSUNTO
}

\subsection{Introdução}

Processos de dispersão são encontrados em diversas situações na natureza, como epidemias ou incêndios em florestas, por exemplo [28-31]. Tais fenômenos geralmente são caracterizados por dois processos que competem entre si: a tendência de espalhamento, como no caso de uma doença infecciosa onde o agente transmissor pode contaminar os seus vizinhos, aumentando assim o alcance da doença, e a tendência de retração, como no caso da mesma doença infecciosa quando um indivíduo contaminado pode se recuperar diminuindo o alcance da doença. Se o processo de contaminação supera o processo de recuperação, então todo o sistema atingirá um estado no qual haverá um equilíbrio entre os indivíduos infectados e sadios, ao passo que, se a recuperação supera a contaminação o agente contaminador tenderá a diminuir em quantidade até que eventualmente desapareça.

Modelos para processos de dispersão têm despertado grande interesse nos últimos tempos, principalmente no estudo de transições de fase entre a extinção e a sobrevivência dos indivíduos. E o modelo mais simples que exibe esta transição é a Percolação Dirigida. Neste modelo consideramos uma rede na qual os sítios componenetes podem estar ativos (contaminados, ocupados, etc.) ou inativos, e dependendo de algum parâmetro de controle o balanço entre a disseminação dos sítios ativos e a sua recuperação pode ser favorável à ocupação, levando toda a rede 
ao estado de atividade, ou pode ser favorável à recuperação, levando toda a rede ao estado inativo ou absorvente. Como o sistema pode alcançar o estado absorvente mas não pode mais abandoná-lo uma vez que o atinja, o modelo não pode obedecer o balanço detalhado, o que significa que a PD é um processo fora do equilíbrio. A transição entre o estado ativo e o absorvente é contínua e caracterizada por um comportamento crítico universal.

Em muitos aspectos o comportamento crítico fora do equilíbrio da PD se assemelha ao dos modelos de transição no equilíbrio. Particularmente é possível lançar mão dos conceitos de invariância de escala e identificar vários expoentes críticos, que, como nos processos de transição no equilíbrio, permitem classificar as transições de fase em classes de universalidade.

\subsection{Processo difusivo}

\subsubsection{Da difusão isotrópica à Percolação Dirigida}

Sendo considerada frequentemente um processo dinâmico, a PD foi originalmente definida como um modelo geométrico para conectividade em meios randômicos onde ocorre a difusão isotrópica, como por exemplo um material poroso onde poros vizinhos são conectados por canais de permeabilidade variável [32,33].

Na difusão isotrópica, ou Percolação ordinária, o invasor se espalha isotropicamente em todas as direções do espaço. Um dos modelos mais simples deste processo é a Percolação por ligações em uma rede quadrada $d$-dimensional. Neste modelo os canais do meio poroso são representados por ligações entre sítios adjacentes de uma rede quadrada. Essas ligações têm probabilidade $p$ de estarem abertas e consequentemente $(1-p)$ de estarem fechadas. Por simplicidade as ligações são consideradas independentes. Intuitivamente podemos concluir que se 
$p$ é relativamente grande, a profundidade de espalhamento do agente propagador é grande, ao passo que se $p$ é relativamente pequena, a profundidade de espalhamento é pequena, de modo que grandes partes do material podem ser consideradas impermeáveis. Ambos regimes são separados por uma transição de fase contínua em $p$.
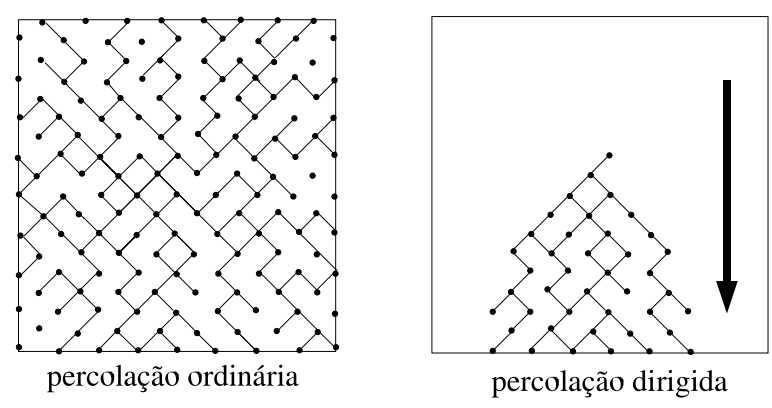

Figura 3: Percolação Ordinária e Dirigida numa rede quadrada diagonal com condições de contorno livres.

O lado esquerdo da Figura 3 mostra uma configuração típica de ligações abertas e fechadas em duas dimensões. Cada sítio gera um certo aglomerado de sítios conectados correspondendo ao maior alcance de difusão do agente propagador. O sítio a partir do qual o aglomerado se forma é chamado origem, e o tamanho do aglomerado é igual ao número de sítios conectados. Note que diferentes origens podem gerar o mesmo aglomerado, de forma que toda a rede pode ser decomposta em um conjunto de aglomerados ligados.

A Percolação Dirigida, introduzida em 1957 por Broadbent e Ham- 
mersley [34], é uma variante anisotrópica da percolação ordinária. Como se pode ver no lado direito da Figura 3 esta variante introduz uma direção preferencial no espaço. As ligações funcionam como válvulas no sentido de que o agente propagador somente pode se espalhar ao longo de direções específicas, como está indicado pela seta na figura em questão. Como um exemplo podemos pensar num meio poroso sob a ação de uma força gravitacional que obriga o invasor a se espalhar sempre na direção do campo de forças. Deste modo, partindo de uma determinada posição, o aglomerado resultante é um subconjunto do aglomerado correspondente no caso isotrópico.

As transições de fase tanto no caso da percolação ordinária quanto na dirigida são similares em muitos aspectos. Ambas podem ser caracterizadas por um parâmetro de ordem $P_{\infty}$ que é definido como a probabilidade de que um sítio aleatoriamente escolhido seja origem de um aglomerado infinito. Se $P_{\infty}>0$, finito, o invasor pode se espalhar por distâncias arbitrariamente grandes, de modo que o sistema esteja na fase considerada permeável. Se $P_{\infty}=0$ o sistema cai no estado dito impermeável, onde o invasor possui um alcance finito dentro do meio poroso.

Embora a percolação ordinária e a dirigida possuam muitas características em comum, seu comportamento crítico tende a ser bastante diferente. No caso isotrópico, as propriedades críticas são as mesmas em qualquer direção que se estude, de modo que as correlações de longo alcance presentes são rotacionalmente invariantes. Por causa de sua simetria o ponto crítico da percolação ordinária é $p_{c}=1 / 2$ [33]. Contrariamente, as propriedades críticas da PD refletem a sua anisotropia espacial, levando a diferentes expoentes críticos. Em contraste com o caso isotrópico, os valores numéricos do ponto crítico e dos expoentes na Percolação Dirigida ainda não são analiticamente conhecidos e parecem ser dados por números irracionais. 


\subsubsection{Percolação Dirigida: um Processo Dinâmico}

Considerando a direção de propagação como 'tempo', a PD pode ser considerada como um processo dinâmico em $d+1$ dimensões que descreve o espalhamento de algum agente não conservativo. Por exemplo, a PD pode ser vista como um modelo simples para a disseminação epidêmica de uma doença infecciosa sem controle [35]. A popularidade da interpretação dinâmica da PD se deve em parte ao fato de que a formulação dependente do tempo é naturalmente aplicada na simulação computacional dos sistemas modelados.

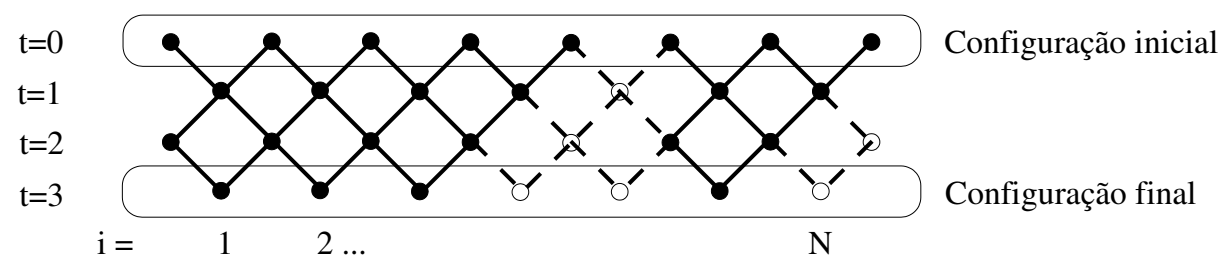

Figura 4: Percolação Dirigida em 1+1 dimensões interpretada como um processo estocástico dependente do tempo. Ligações abertas são indicadas pelas linhas cheias e os sítios ativos pelos círculos preenchidos. A regra de atualização deste sistema é dada pela equação (1)

A interpretação dinâmica da Percolação Dirigida é ilustrada na Figura 4 onde os sítios da rede são numerados horizontalmente por meio de um índice $i$ e verticalmente por meio de uma variável de tempo discreta $t$. Uma variável local binária $s_{i}(t)$ é relacionada a cada sítio. Se $s_{i}=1$ isto significa que o sítio $i$ está ativo, enquanto que se $s_{i}=0$ o sítio $i$ está inativo. O conjunto $s=\left\{s_{i}\right\}$ em um dado tempo $t$ define a configuração do sistema.

Para uma dada configuração do sistema, em um tempo $t$, a configuração no tempo seguinte $(t+1)$ pode ser determinada como segue: para cada par de ligações entre os sítios $(i, i+1, t)$ e $(i, t+1)$ dois números aleatórios $z_{i}^{ \pm} \in(0,1)$ são gerados. A ligação é considerada aberta (com probabilidade $p$ ) se $z_{i}^{ \pm}<p$, levando à seguinte 
regra de atualização:

$$
s_{i}(t+1)= \begin{cases}1 & \text { se } s_{i}(t)=1 \text { e } z_{i}^{-}<p \\ 1 & \text { se } s_{i+1}(t)=1 \text { e } z_{i}^{+}<p \quad \text { e } \\ 0 & \text { nos demais casos. }\end{cases}
$$

Como em qualquer sistema dinâmico, precisamos especificar as condições iniciais, e as mais comumente utilizadas são: rede completamente cheia, sítios aleatoriamente escolhidos ativos ou um único sítio ativo no centro da rede (semente ativa).

Mesmo as simulações numéricas mais simples demonstram que a evolução temporal de um processo de PD muda significativamente na transição de fase. Diagramas espaço-tempo para condições iniciais aleatórias são mostradas na parte superior da Figura 5. Para $p<p_{c}$ o número de sítios ativos diminui exponencialmente com o tempo até que o sistema alcance o estado absorvente, ao passo que para $p>p_{c}$ o número médio de sítios ativos atinge um valor de saturação, constante, com o tempo. Para $p \sim p_{c}$ o número médio de sítios ativos decai mais lentamente do que no caso anterior, sendo um decaimento em lei de potência, e os aglomerados formados lembram estruturas fractais. Um comportamento semelhante pode ser observado quando o processo de Percolação Dirigida se inicia a partir de uma semente ativa, como podemos examinar na parte inferior da Figura 5.

É sempre bom considerar a Percolação Dirigida como um processo reação-difusão de partículas interagentes. Associando sítios ativos com com partículas do tipo $A$ e inativos como buracos representados por $\emptyset$, tal processo corresponde ao seguinte esquema de reações: 


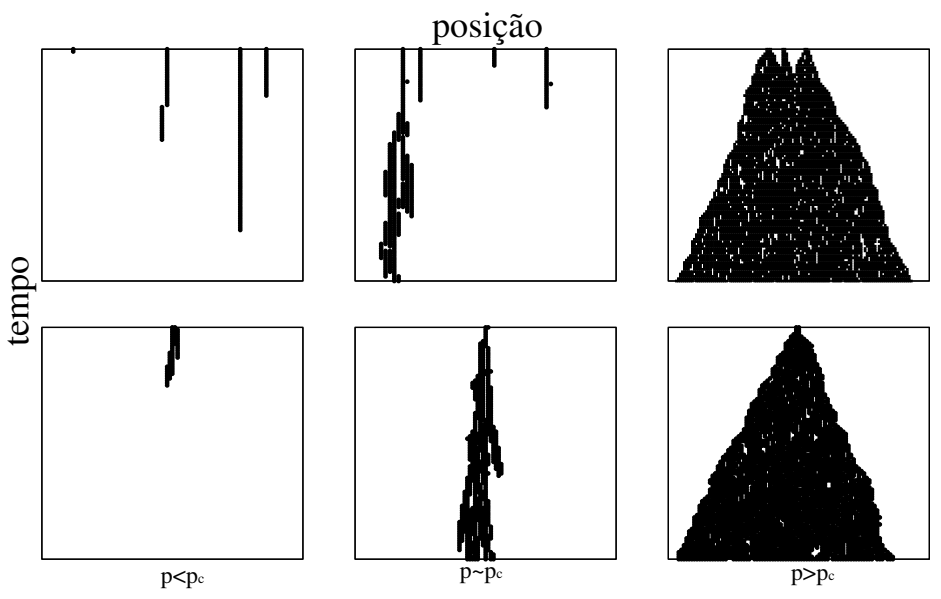

Figura 5: Percolação Dirigida em 1+1 dimensões com condições iniciais aleatórias (acima) e com semente ativa (abaixo).

$$
\begin{array}{ll}
\text { auto-destruição: } & A \rightarrow \emptyset, \\
\text { difusão: } & \emptyset+A \rightarrow A+\emptyset, \\
\text { replicação: } & A \rightarrow 2 A, \\
\text { fusão: } & 2 A \rightarrow A .
\end{array}
$$

Para entender o esquema (2) consideremos novamente o exemplo da Figura 4. Dependendo da configuração das ligações, cada sítio ativo (partícula) pode ativar dois sítios vizinhos na linha subsequente (instante $t+1$ ). Se as duas ligações estão fechadas, a partícula se auto-destrói. Se somente uma ligação está aberta, a partícula irá difundir para a direita ou para a esquerda com igual probabilidade. Quando as duas ligações estão abertas, a partícula pode se difundir para um dos lados replicando-se para o outro lado. Por outro lado, se duas partículas alcançam o mesmo sítio no passo seguinte, elas coalescem numa única partícula, o que limita a densidade máxima de sítios ativos. 


\section{PERCOLAÇÃO DIRIGIDA 2.3 Modelos de Rede para Percolação Dirigida}

\subsection{Modelos de Rede para Percolação Dirigida}

Na literatura existe uma grande variedade de modelos de PD seguindo o espírito do esquema de reação-difusão apresentado. Mas todos eles apresentam o mesmo comportamento crítico. A característica comum de esses modelos é que todos eles apresentam um estado absorvente, ou seja, uma configuração na qual o sistema pode chegar mas da qual não pode sair. Em muitos casos o estado absorvente é justamente a rede vazia. A existência do estado absorvente implica que certos processos microscópicos são proibidos, como por exemplo a criação expontânea $(\emptyset \rightarrow A)$. A seguir discutiremos alguns exemplos de modelos para processos de PD.

\subsubsection{Autômato Celular de Domany-Kinzel}

Vários autômatos celulares são conhecidos por apresentarem transições de fase do tipo Percolação Dirigida entre um estado flutuante e um absorvente. O modelo mais simples desta classe é o modelo (1+1)-dimensional de Domany-Kinzel (DK) [36], que é definido numa rede quadrada diagonal e evolui por atualizações paralelas de acordo com certas probabilidades condicionais de transição $P\left[s_{i}(t+\right.$ 1) $\left.\mid s_{i}(t), s_{i+1}(t)\right]$. Essas probabilidades dependem de dois parâmetros e são definidas por:

$$
\begin{aligned}
& P[1 \mid 0,0]=0, \\
& P[1 \mid 0,1]=P[1 \mid 1,0]=p_{1}, \\
& P[1 \mid 1,1]=p_{2}
\end{aligned}
$$

O esquema de atualização correspondente pode ser visualizado pelo seguinte algoritmo (Figura 6): para cada sítio $s_{i}$ geramos um número aleatório uniforme $z_{i}(t+1)$ no intervalo $(0,1)$ e definimos 


\section{PERCOLAÇÃO DIRIGIDA 2.3 Modelos de Rede para Percolação Dirigida}

$$
s_{i}(t+1)=\left\{\begin{array}{lll}
1 & \text { se } s_{i}(t) \neq s_{i+1}(t) & \text { e } z_{i}(t+1)<p_{1} \\
1 & \text { se } s_{i}(t)=s_{i+1}(t)=1 & \text { e } z_{i}(t+1)<p_{2} \\
0 & \text { nos demais casos } &
\end{array}\right.
$$
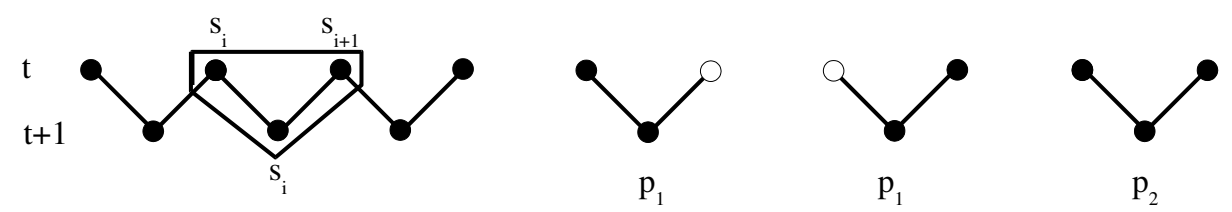

Figura 6: Probabilidades de atualização no autômato celular (1+1)-dimensional de DomanyKinzel

O modelo DK depende de duas probabilidades de percolação, $p_{1}$ e $p_{2}$. O diagrama de fases correspondente é mostrado na Figura 7. O gráfico apresenta uma fase ativa e uma inativa separadas por uma linha de transição de fase. $\mathrm{Na}$ fase ativa o modelo atinge um estado estacionário flutuante, enquanto que na fase inativa sempre atinge o estado absorvente.

Existem fortes evidências numéricas de que o comportamento crítico ao longo de toda a linha de transição de fase seja característico de PD, ou seja, essas transições de fase apresentam o mesmo tipo de correlações de longo alcance. As correlações de curto alcance, entretanto, não são universais e podem mudar ao longo da linha de transição da Figura 7. Na transição de fase o estado estacionário possui um aglomerado ativo cujo tamanho médio cresce com o aumento de $p_{2}$, sendo o mínimo quando $p_{2}=0$ e divergindo quando $p_{2} \rightarrow 1$. No caso $p_{2}=1$ o comportamento crítico do sistema muda, pois passa a presentar dois estados absorventes: o estado totalmente vazio, quando todos os sítios são inativos, e o estado totalmente cheio, quando todos os sítios são ativos. Este caso especial é conhecido como Percolação Dirigida Compacta [37] e suas propriedades críticas 
são completamente diferentes daquelas da PD [38].

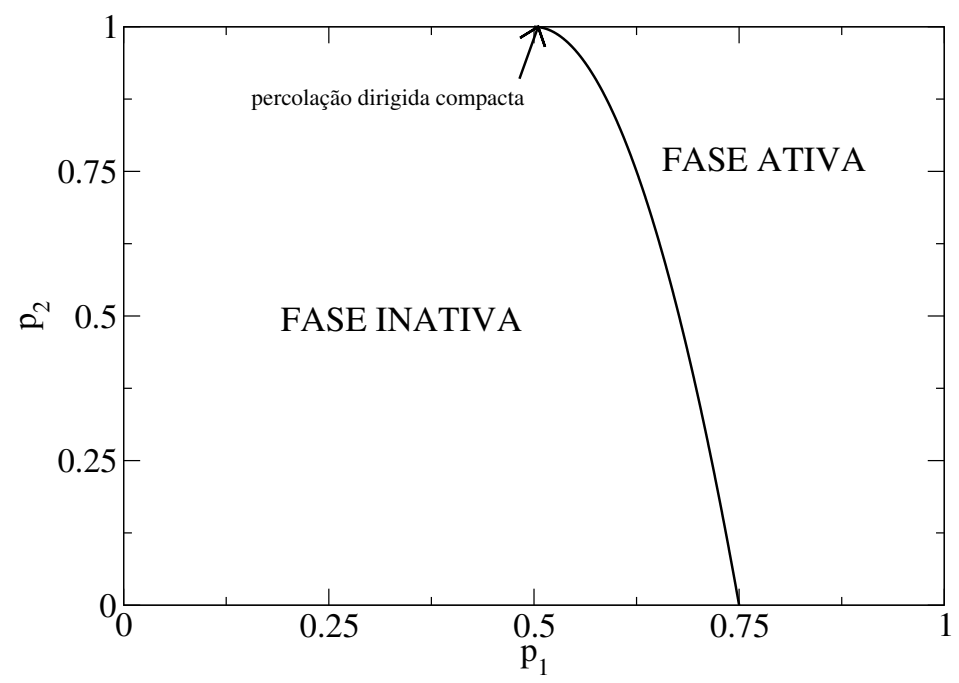

Figura 7: Diagrama de fases do modelo de Domani-Kinzel

Em mais de uma dimensão o modelo DK pode ser definido por atualizações locais com probabilidades condicionais $P\left(s_{i}(t+1) \mid n_{i}(t)\right)$ dependendo do número $n_{i}(t)$ de sítios ativos na vizinhança do sítio $i$. Portanto o modelo é controlado por $2 d$ parâmetros $p_{1}, p_{2}, \ldots, p_{2 d}$ com probabilidades condicionais definidas por:

$$
\begin{aligned}
& P[1 \mid 0]=0, \\
& P[1 \mid n]=p_{n} .
\end{aligned}
$$

\subsubsection{O Processo de Contato}

Um outro importante modelo de rede é o Processo de Contato. Em contraste com os autômatos celulares, este modelo utiliza atualização assíncrona. O processo de contato foi introduzido por Harris [35] como um modelo de disseminação de epidemias sem controle. Aqui os sítios da rede representam indivíduos sadios 


\section{PERCOLAÇÃO DIRIGIDA 2.3 Modelos de Rede para Percolação Dirigida}

ou infectados. Indivíduos infectados podem igualmente se curar ou infectar outros indivíduos sadios em cada iteração. Dependendo das taxas relativas de infecção e de recuperação, a doença pode se espalhar pela população inteira ou pode desaparecer após algum tempo.

O processo de contato é definido como uma rede regular d-dimensional cujos sítios podem estar ativos ou inativos. A cada tentativa de atualização de um sítio $i$, dependendo do seu estado $s_{i}(t)$ e do número de vizinhos ativos $n_{i}(t)$, um novo valor $s_{i}(t+d t)=0,1$ é atribuído de acordo com certas taxas de transição $\omega\left[s_{i}(t) \rightarrow s_{i}(t+d t), n_{i}(t)\right]$. No caso do processo de contato padrão, essas taxas são definidas por:

$$
\begin{aligned}
& \omega[0 \rightarrow 1, n]=\lambda n / 2 d, \\
& \omega[1 \rightarrow 0, n]=1,
\end{aligned}
$$

onde o parâmetro $\lambda$ controla a taxa de infecção e desempenha o papel de probabilidade de percolação. [39-41]

De modo geral a taxa de infecção de um indivíduo no processo de contato é dado por $\lambda n_{o} / Z$ onde $n_{o}$ é o número de primeiros vizinhos ocupados e $Z$ é o número de coorenação da rede [42-44] . Indivíduos se curam com taxa 1, mas se utilizarmos uma definição diferente da taxa de infecção, $n_{o} / Z$ a taxa de cura passa a ser

$$
\gamma=1 / \lambda .
$$

Indivíduos sadios que possuam vizinhos doentes passam a ter um significado bastante importante, pois somente eles podem ser contaminados. Esses indivíduos são denominados indivíduos ativos e seu número efetivo é definido por: 


$$
n_{a}=\sum_{i} \frac{n_{o}^{i}}{Z}
$$

onde a soma é feita sobre todos os indivíduos sadios $i$ e $n_{o}^{i}$ é o número de vizinhos infectados em relação ao indivíduo $i$.

Como podemos perceber pela equação 8, o número médio de indivíduos ativos no sistema é justamente a taxa média de infecção, ou seja, representa quanto o número médio de indivíduos infectados $\left\langle n_{p}\right\rangle$ cresce em cada unidade de tempo. Desse modo, no estado estacionário, a taxa de cura do sistema pode ser dada por:

$$
\gamma=\frac{<n_{a}>}{<n_{p}>}
$$

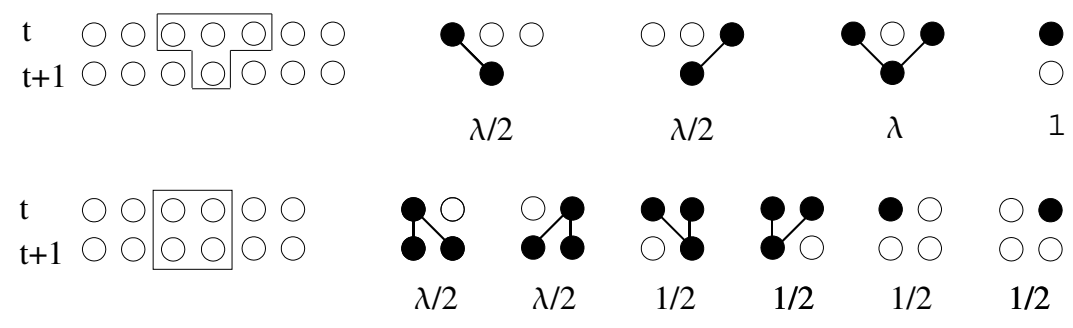

Figura 8: Processo estocástico no processo de contato (1+1)-dimensional. Sítios infectados (círculos cheios) contaminam seus vizinhos à uma taxa $\lambda / 2$ e se recuperam à uma taxa 1 . A parte superior mostra as regras de atualização de acordo com a equação (6). A parte inferior mostra uma definição equivalente ao processo de dois sítios

\subsubsection{O processo de contato conservativo}

De acordo com a Mecânica Estatística do equilíbrio, se dois ensembles de Gibbs diferentes são utilizados para se calcular a mesma grandeza termodinâmica, 


\section{PERCOLAÇÃO DIRIGIDA 2.3 Modelos de Rede para Percolação Dirigida}

o resultado será o mesmo, inclusive para sistemas que apresentam transições de fase [45-47]. Existe um procedimento padrão de passagem de um ensemble para outro, sendo que a principal característica dessa conversão é que uma quantidade que funcione como um parâmetro fixo no sistema original se torna uma variável. Para sistemas longe do equilíbrio esse procedimento padrão não existe, porém Ziff e Brosilow [48] mostraram que é possível aplicar a mesma propriedade dos sistemas em equilíbrio. Com base nesse procedimento, Tomé e Oliveira [10] introduziram o conceito de Processo de Contato Conservativo, onde é feita uma transformação no sistema de modo que o número de partículas, que é uma grandeza variável no Processo de Contato ordinário, passa a ser uma grandeza constante, pagando por isso o preço de tornar variável a taxa de cura dada pela equação 9

Como no Processo de Contato Conservativo o número de indivíduos infectados é constante não há mais processos de cura ou de contaminação. Em vez disso, quando um indivíduo ativo, de forma idêntica à do Processo de Contato ordinário, passaria a ser contaminado, um outro indivíduo contaminado é escolhido ao acaso e troca de lugar com o indivíduo sadio que estava prestes a ser contaminado. Deste modo o sistema jamais atinge o estado absorvente, onde todos são sadios, o que é muito significativo do ponto de vista computacional. Neste modelo a taxa de cura apresentada pela equação 9 é dada simplesmente por:

$$
\gamma=\frac{<n_{a}>}{n} .
$$

\subsubsection{O modelo Ziff-Gulari-Barshad para catalise heterogênea}

Muitas reações catalíticas se encaixam e modelos de PD. A propriedade chave dessas reações é a existência de estados cataliticamente viciados dos quais o sistema não pode sair, uma vez que sejam alcançados. Uma reação catalítica simples, porém muito importante nos dias de hoje é a oxidação, em superfície de platina, do 


\section{PERCOLAÇÃO DIRIGIDA 2.3 Modelos de Rede para Percolação Dirigida}

monóxido de carbono (CO) que, produzido pela queima de combustíveis fósseis, é extremamente nocivo ao ser humano (Figura 9). Um modelo simples para esta reação foi proposto em 1986 por Ziff, Gulari e Barshad (ZGB) [49]. O modelo é descrito por um gás composto de $\mathrm{CO}$ e $\mathrm{O}_{2}$, em concentrações individuais fixas $y$ e $1-y$ respectivamente, que é colocado em contato com uma superfície catalítica representada por uma rede quadrada cujos sítios podem estar vazios $(\emptyset)$, ocupados por uma molécula de monóxido de carbono $(\mathrm{CO})$ ou ocupados por um átomo de oxigênio $(\mathrm{O})$.

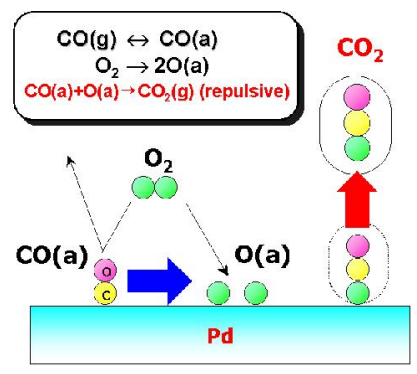

Figura 9: Esquema da reação de oxidação do monóxido de carbono em superfície de platina.

O modelo ZGB evolui por atualizações randômicas seqüenciais que respeitam as seguintes regras probabilísticas:

1. As moléculas de $\mathrm{CO}$ ocupam qualquer sítio desocupado com taxa $y$;

2. As moléculas de $\mathrm{O}_{2}$ se dissociam na superfície catalítica em dois átomos de $\mathrm{O}$ e ocupam dois sítios vazios adjacentes com taxa $1-y$;

3. Moléculas de $\mathrm{CO}$ e átomos de $\mathrm{O}$ vizinhos se recombinam instantaneamente produzindo uma molécula de $\mathrm{CO}_{2}$ que se solta da superfície catalítica deixando em seu lugar dois sítios vazios.

Na rede essas três regras são representadas pelo seguinte esquema: 


\section{PERCOLAÇÃO DIRIGIDA 2.3 Modelos de Rede para Percolação Dirigida}

$$
\begin{array}{ll}
\emptyset \rightarrow C O & \text { com taxa } y \\
\emptyset+\emptyset \rightarrow O+O & \text { com taxa } 1-y \\
O+C O \rightarrow \emptyset+\emptyset & \text { instantaneamente }
\end{array}
$$

Claramente o esquema (11) é irreversível e portanto o processo dinâmico não obedece o balanço detalhado. Além disso, se a rede for totalmente ocupada por moléculas de $\mathrm{CO}$ ou por átomos de $\mathrm{O}$ o sistema cai num estado absorvente saturado, o que depende da taxa $y$. O modelo apresenta duas transições de fase, sendo uma delas do estado saturado $[\mathrm{O}]$ para o estado catalítico ativo em $y_{1}$ e a outra do estado ativo para o estado saturado [CO] em $y_{2}$. A Figura 10 apresenta um diagrama de fases esquemático do modelo. A transição $y=y_{1}$ é do tipo PD e seus expoentes críticos foram estimados numericamente [50-52], embora até hoje não tenham sido observados experimentalmente.

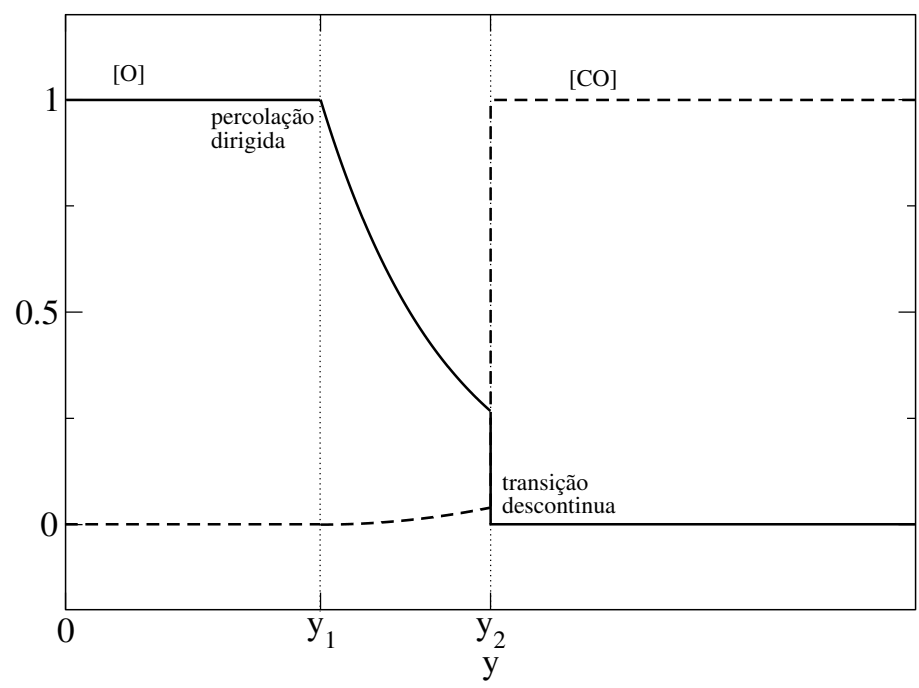

Figura 10: Diagrama de fases esquemático do modelo ZGB. A linha cheia representa a concentração de oxigênio e a linha pontilhada a concentração de monóxido de carbono. 


\subsection{Leis de Escala}

Na física estatística no equilíbrio as transições de fase contínuas são usualmente caracterizadas por leis de escala universais. Por exemplo, a magnetização, enquanto parâmetro de ordem, na fase ordenada do modelo de Ising bidimensional se anula nas proximidades do ponto crítico de acordo com $\left|T-T_{c}\right|^{\beta}$. Da mesma forma o comprimento de correlação $\xi$ diverge conforme $\left|T-T_{c}\right|^{-\nu}$. No ponto crítico o comprimento de correlação é infinito, o que significa que não existe comprimento de escala no sistema. Consequentemente, no ponto crítico o sistema se torna invariante frente a transformações de escala. Nos casos longe do equilíbrio podemos encontrar um comportamento parecido nas transições de fase, de modo que apresentaremos a seguir uma teoria de escala fenomenológica que possa ser aplicada à PD e a outros tipos de transição em estados absorventes.

\subsubsection{Os expoentes críticos $\beta, \nu_{\perp}, \nu_{\|}, \delta, \eta$ e $z$}

O parâmetro de ordem de um processo de espalhamento é a densidade de sítios ativos, dada pela seguinte expressão:

$$
\rho(t)=<\frac{1}{N} \cdot \sum_{i} s_{i}(t)>
$$

onde a notação $\langle\ldots>$ representa a média sobre todos os possíveis estados do sistema. Considerando primeiramente um sistema infinito, $\rho(t)$ decai e eventualmente se satura em algum valor estacionário $\rho^{\text {stat }}$. A densidade estacionária varia continuamente com $p-p_{c}$ e se anula no ponto crítico. Nas proximidades da transição o parâmetro de ordem varia de acordo com uma lei de potência

$$
\rho^{\text {stat }} \sim\left(p-p_{c}\right)^{\beta}
$$


onde $\beta$ é o expoente crítico associado à densidade de sítios ativos. Num gráfico log$\log$ a lei de potência se comporta como uma reta cuja inclinação é $\beta$. O valor de $\beta$ depende da dimensionalidade do sistema.
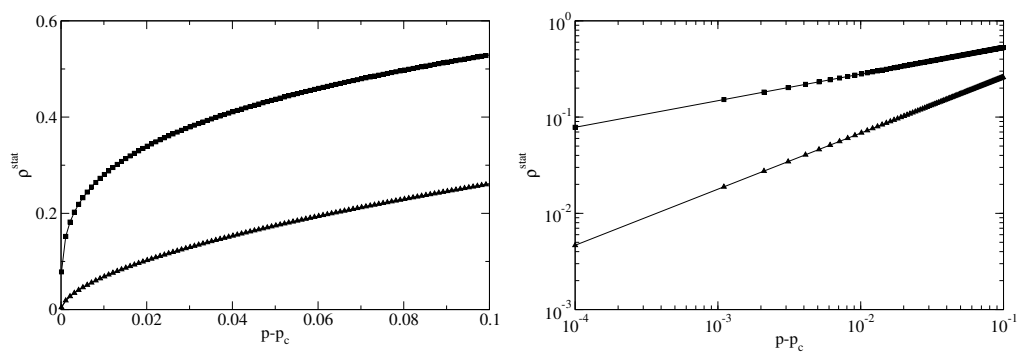

Figura 11: Densidade estacionária $\rho^{\text {stat }}$ na fase ativa para Percolação Dirigida em $1+1$ (quadrados) e 2+1 (triângulos) dimensões, em escala linear (esquerda) e log-log.

Os processos de espalhamento também podem ser caracterizados por certos comprimentos de correlação. Diferentemente dos modelos no equilíbrio, que são estáticos, fenômenos críticos longe do equilíbrio envolvem o 'tempo' como uma dimensão adicional. Uma vez que as propriedades temporais e as espaciais são diferentes no sistema, é necessário fazer uma diferenciação entre elas. Aqui a diferenciação será feita com o uso dos índices $\perp$ e $\|$ representando propriedades espaciais e temporais respectivamente. Assim sendo, como as transições de fase longe do equilíbrio são caracterizadas por dois comprimentos de correlação independentes, um associado ao tempo e outro ao espaço, esses comprimentos de correlação são: $\xi_{\perp}$ (comprimento de correlação espacial) e $\xi_{\|}$(comprimento de correlação temporal). Nas proximidades da transição, esses comprimentos de escala devem divergir conforme

$$
\begin{aligned}
\xi_{\perp} & \sim\left|p-p_{c}\right|^{-\nu_{\perp}} \\
\xi_{\|} & \sim\left|p-p_{c}\right|^{-\nu_{\|}}
\end{aligned}
$$

com expoentes críticos $\nu_{\|}$e $\nu_{\perp}$ geralmente diferentes. No regime de escala, ou seja, nas proximidades da transição, os dois comprimentos de correlação se relacionam por: 


$$
\xi_{\perp} \sim \xi_{\|}^{-\frac{2}{z}}
$$

onde

$$
z=2 \nu_{\perp} / \nu_{\|}
$$

que é chamado expoente dinâmico. Em muitos modelos o conjunto $\beta, \nu_{\|}$e $\nu_{\perp}$ é o que define a classe de universalidade. Transições de fase fora do equilíbrio são ditas pertencentes à mesma classe de universalidade quando possuem os mesmo expoentes críticos, assim como no caso das transições no equilíbrio.
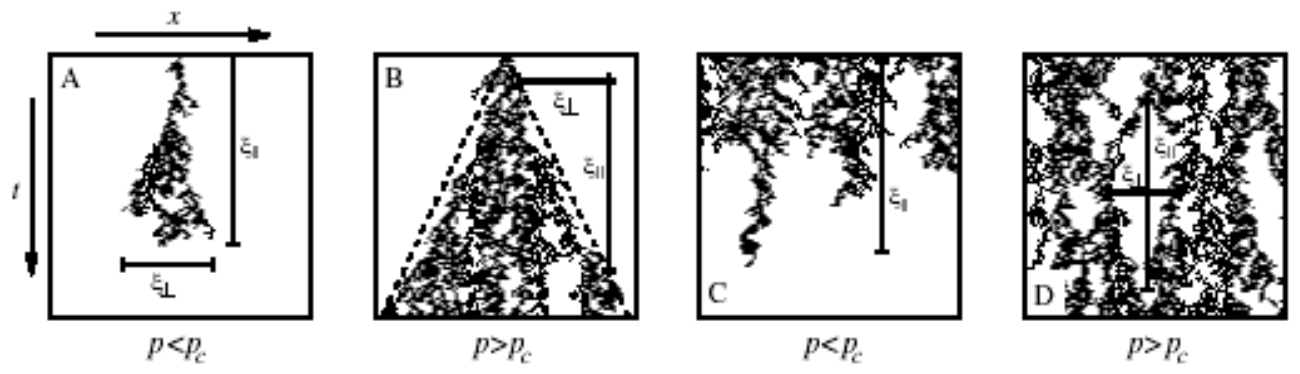

Figura 12: Interpretação geométrica dos comprimentos de correlação $\xi_{\|}$e $\xi_{\perp}$.

Além da densidade de partículas no sistema, outras propriedades interessantes das quais podemos extraír informações são a probabilidade de sobrevivência $P(t)$, o número médio de indivíduos na rede $N(t)$ e o espalhamento da população $R^{2}(t)$. A medida de $N(t)$ é feita da seguinte forma:

$$
N(t)=<\sum_{i} s_{i}(t)>,
$$

enquanto que $P(t)$ é a razão entre o número de amostras de um experimento que ainda não atingiram o estado absorvente num determinado tempo $t$ e o número 
total de amostras. $R^{2}(t)$ é a soma dos quadrados das distâncias de cada partícula em relação à origem, conforme definida na seção 2.2.1.

Para $p<p_{c}$ tanto $P(t)$ quanto $N(t)$ decaem exponencialmente

$$
N(t) \propto P(t) \propto e^{-\lambda t},
$$

e o expoente $\lambda$ varia com $\left|p-p_{c}\right|$ de acordo com uma lei de potência onde

$$
-\lambda \propto\left|p-p_{c}\right|^{\nu_{\|}} .
$$

Para $p>p_{c}$ a fronteira entre a população ativa e o vácuo cresce em média com velocidade constante $v\left(p-p_{c}\right)$. Para $p \sim p_{c}$ o sistema sempre cai no estado absorvente, mas o tempo necessário para que isto aconteça diverge. Dessa forma a evolução assintótica do sistema segue leis de potência:

$$
\begin{aligned}
& P(t) \propto t^{-\delta} \\
& N(t) \propto t^{\eta}
\end{aligned}
$$

e

$$
R^{2}(t) \propto t^{z} .
$$

Os valores estimados desses expoentes críticos, de acordo com a dimensão do sistema, estão descritos na tabela $1[42,53]$. 


\begin{tabular}{|c|c|c|c|c|}
\hline & $d=1$ & $d=2$ & $d=3$ & $d=4$ \\
\hline$\beta$ & $0.27649(4)$ & $0.583(4)$ & $0.805(10)$ & 1 \\
\hline$\nu_{\|}$ & $1.73383(3)$ & $1.295(6)$ & $1.105(5)$ & 1 \\
\hline$\nu_{\perp}$ & $1.09684(6)$ & $0.733(4)$ & $0.581(5)$ & $1 / 2$ \\
\hline$\delta$ & $0.15947(3)$ & $0.4505(10)$ & $0.730(4)$ & 1 \\
\hline$\eta$ & $0.31368(4)$ & $0.2295(10)$ & $0.114(4)$ & 0 \\
\hline$z$ & $1.26523(3)$ & $1.1325(10)$ & $1.052(3)$ & 1 \\
\hline
\end{tabular}

Tabela 1: Expoentes críticos em função da dimensão do sistma.

\subsubsection{Percolação Dirigida Compacta}

Relembrando o modelo de Domani-Kinzel (Figura 7) notamos que para cada valor de $p_{2}$ existe um correspondente valor de $p_{1}$ tal que o sistema transiciona da fase ativa para a inativa, onde todos os sítios estão inativos e de onde o sistema não pode escapar, sendo assim um estado absorvente. Entretanto, no caso específico de $p_{2}=1$ o sistema passa a contar com dois possíveis estados absorventes, sendo o primeiro aquele onde a rede está completamente inativa e o segundo onde a rede está completamente ativa, pois como $p_{2}=1$, a partir do esquema de atualizações descrito pela equação 4, é impossível o decaimento de um sítio ativo. Esta transição de fase é descontínua e por isso não pode pertencer à classe de universalidade da Percolação Dirigida. Seus comportamento crítico, no entanto, também segue leis de potência e os expoentes críticos são dados pelos valores presentes na tablea 2 . 


\begin{tabular}{|c|c|}
\hline$\beta$ & 0 \\
\hline$\nu_{\|}$ & 2 \\
\hline$\nu_{\perp}$ & 1 \\
\hline$\delta$ & $1 / 2$ \\
\hline$\eta$ & 0 \\
\hline$z$ & 1 \\
\hline$\beta^{\prime}$ & 1 \\
\hline
\end{tabular}

Tabela 2: Expoentes críticos da Percolação Dirigida Compacta. [1]

Neste caso lançamos mão de um outro expoente crítico chamado $\beta^{\prime}$ obtido através do comportamento assintótico da probabilidade de sobrevivência $P(t)$.

$$
P(t \rightarrow \infty) \propto\left|p-p_{c}\right|^{\beta^{\prime}},
$$

Para transições de fase contínuas $\beta=\beta^{\prime}$, o que não é válido para transições descontínuas. O conjunto de expoentes críticos neste caso determina uma nova classe de universalidade diferente da Percolação Dirigida. Através da comparação entre os expoentes críticos $\nu_{\perp}$ presentes nas tabelas 1 (para uma dimensão) e 2 notamos que o cluster crítico no caso da transição descontínua é mais compacto. Por esse motivo a classe de universalidade regida pelo conjunto de expoentes críticos da tabela 2 é chamada de Percolação Dirigida Compacta.

A seguir apresentamos os três modelos de replicação em autômatos celulares, que apresentam transições de fase longe do equilíbrio, sobre os quais trabalhamos caracterizando essas transições, e em seguida mostramos o modelo populacional inspirado no comportamento das cigarras periódicas que mostra uma possível origem para os ciclos primos desses insetos. 


\section{MODELO REPLICADOR-ENZIMA}

\subsection{Introdução}

Num ambiente primitivo, pré-biótico, existiam moléculas capazes de produzir cópias delas próprias, que seriam então chamadas replicadores. Além dos replicadores também existiam outras moléculas que eram incapazes de se copiarem, mas que auxiliavam as reações de replicação dos replicadores, as enzimas.

Considerando a origem da vida como um evento de transição irreversível de um estado desordenado para um estado ordenado, criamos um modelo onde há os replicadores e as enzimas além de uma transição de fase para um estado absorvente. Este modelo foi batizado Modelo Replicador-Enzima, e difere dos outros modelos de replicação autocatalítica, onde replicadores também desempenham o papel de enzimas, por conter enzimas dedicadas que não se replicam, alterando profundamente a dinâmica da população e trazendo um panorama mais coerente com o cenário da evolução pré-biótica.

O modelo Replicador-Enzima é formado por um autômato celular bidimensional onde cada sítio possui três possíveis estados, que são os seguintes:

- sítio vazio;

- sítio ocupado por um replicador;

- sítio ocupado por uma enzima. 
O replicador é aquele indivíduo que tem a capacidade de produzir uma cópia dele mesmo ou de uma enzima, sem auxílio de outros indivíduos, em um dos sítios próximos a ele. A enzima é um indivíduo incapaz de se reproduzir, mas que quando está próximo de um replicador pode auxiliá-lo na produção de uma cópia do replicador para um dos sítios vizinhos dos dois.

Os processos de atualização do autômato são os seguintes:

- Morte: um sítio ocupado por um replicador ou por uma enzima no tempo $t$ passa a estar vazio no tempo $t+1$ com probabilidade $\gamma$;

- Replicação: um sítio vazio no tempo $t$ que possui ao menos um replicador posicionado em um dos quatro sítios primeiros vizinhos a ele passa a estar ocupado por um replicador no tempo $t+1$ com uma probabilidade que depende de um parâmetro $s_{1}$ para cada vizinho ocupado por um replicador;

- Produção de enzima: um sítio vazio no tempo $t$ que possui ao menos um replicador posicionado em um dos quatro sítios primeiros vizinhos a ele passa a estar ocupado por uma enzima no tempo $t+1$ com probabilidade dependente de $s_{p}$ para cada vizinho ocupado por um replicador;

- Catálise ou replicação catalisada: um sítio vazio no tempo $t$ que possui ao menos um replicador posicionado em um dos quatro sítios primeiros vizinhos dele e que num dos sítios vizinhos simultaneamente ao replicador e ao sítio vazio esteja posicionada uma enzima passa a estar ocupado por um replicador no tempo $t+1$ com probabilidade relacionada ao parâmetro $c_{1}$ para cada par replicador-enzima;

- Não ocupação: um sítio vazio no tempo $t$, mas que possui vizinhos replicadores, com presença ou não de enzimas, continua vazio no tempo $t+1 \mathrm{com}$ probabilidade dependente de um parâmetro $k$.

Os diagramas a seguir demonstram esses processos. 

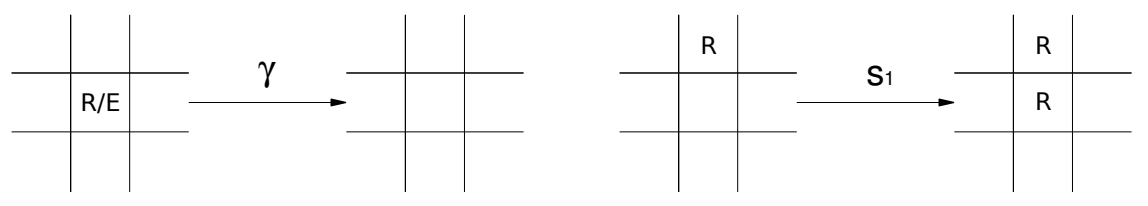

Figura 13: Processos de Morte (à esquerda) e de Replicação
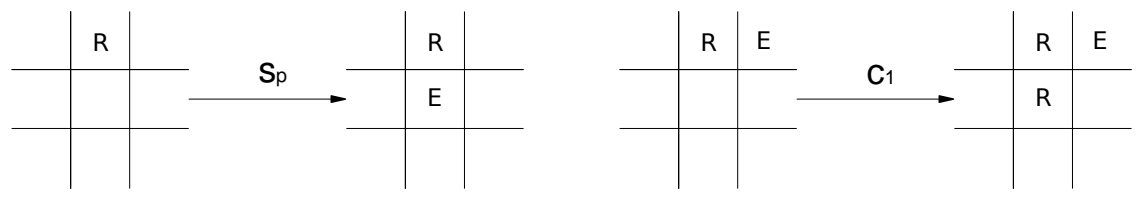

Figura 14: Processos de Produção da enzima (à esquerda) e Catálise

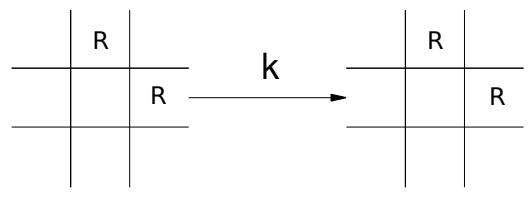

Figura 15: Processo de Não Ocupação 
Sendo assim, considerando um sítio vazio no tempo $t$, as probabilidades de ocupação no tempo $t+1$ são as seguintes:

$$
\begin{gathered}
P_{r}=\frac{n_{r} \cdot s_{1}+n_{c} \cdot c_{1}}{k+n_{r} \cdot\left(s_{1}+s_{p}\right)+n_{c} \cdot c_{1}} \\
P_{e}=\frac{n_{r} \cdot s_{p}}{k+n_{r} \cdot\left(s_{1}+s_{p}\right)+n_{c} \cdot c_{1}} \\
P_{\emptyset}=1-\left(P_{r}+P_{e}\right)
\end{gathered}
$$

onde $P_{r}$ é a probabilidade de um sítio vazio ser ocupado por um replicador, $P_{e}$ a probabilidade de ocupação por uma enzima e $P_{\emptyset}$ a probabilidade de não ocupação. Sendo $n_{r}$ o número de vizinhos ocupados por replicadores e $n_{c}$ o número de pares replicador-enzima vizinhos.

\subsection{Simulações e resultados}

Para realizar as simulações computacionais consideramos uma rede quadrada de dimensão linear 100, com condições de contorno periódicas toroidais. Inicialmente apenas o sítio central da rede está ocupado por um replicador. A cada passo de tempo, ou geração, todos os sítios da rede são atualizados simultaneamente de acordo com as regras de atualização explicitadas na seção anterior. Cada amostra durou no máximo vinte mil geraçoes, pois verificamos que este tempo era suficiente para que a densidade estacionária de sítios ativos fosse atingida, considerando a dimensão linear da rede. Executamos dez mil amostras para cada conjunto de parâmetros $s_{1}, s_{p}$ e $c_{1}$ e calculamos, em média, quantas dessas amostras resultavam numa população em equilíbrio (que não atingiram o estado absorvente em vinte mil gerações). Essa média é a probabilidade de sobrevivência 
estacionária $\Pi=P(t \rightarrow \infty)$ da população. Fizemos gráficos de $\Pi$ contra o parâmetro $s_{1}$, deixando fixo o parâmetro $c_{1}$ e fazendo $s_{p}=\alpha s_{1}$ com $\alpha$ sendo um número real positivo, dos quais extraímos os valores críticos de $s_{1}\left(s_{1}^{*}\right)$. A partir destes valores fizemos os gráficos de $\Pi$ contra $\Delta$, onde $\Delta=s_{1}-s_{1}^{*}$. Dos gráficos de $\Pi$ contra $\Delta$, em escala logarítmica, extraímos os expoentes críticos $\beta^{\prime}$ (conforme equação 23) associados à transição. Em todas as simulações fizemos $\gamma=0.05$ e $k=1$.

A seguir apresentamos alguns gráficos de $\Pi$ contra $s_{1}$ e $\Pi$ contra $\Delta$.

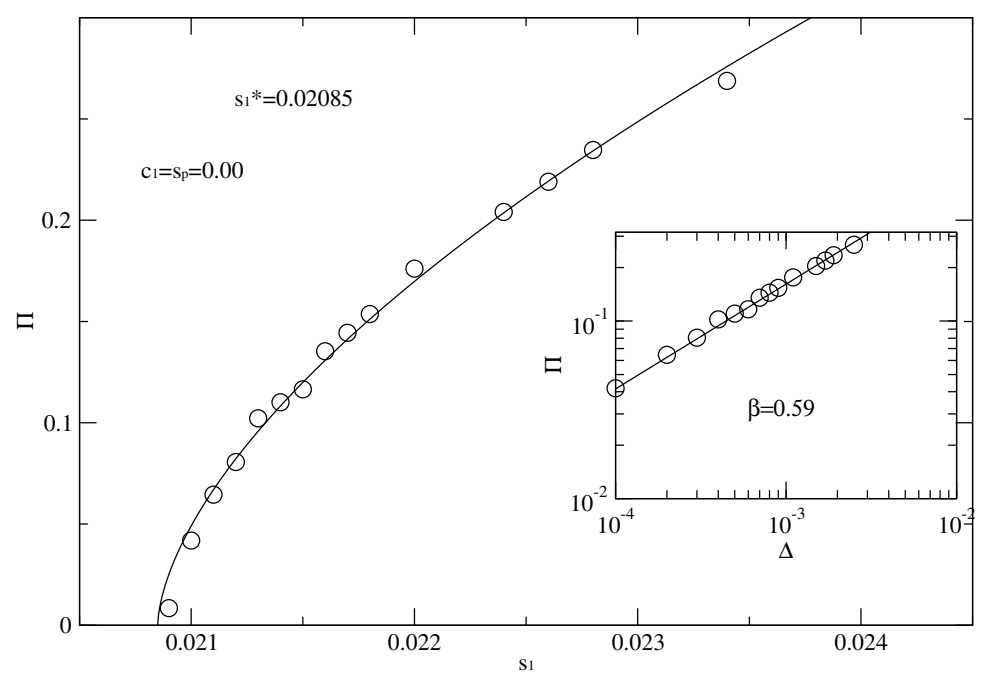

Figura 16: $\Pi$ contra $s_{1}$ e $\Pi$ contra $\Delta-c_{1}=s_{p}=0.00$ 


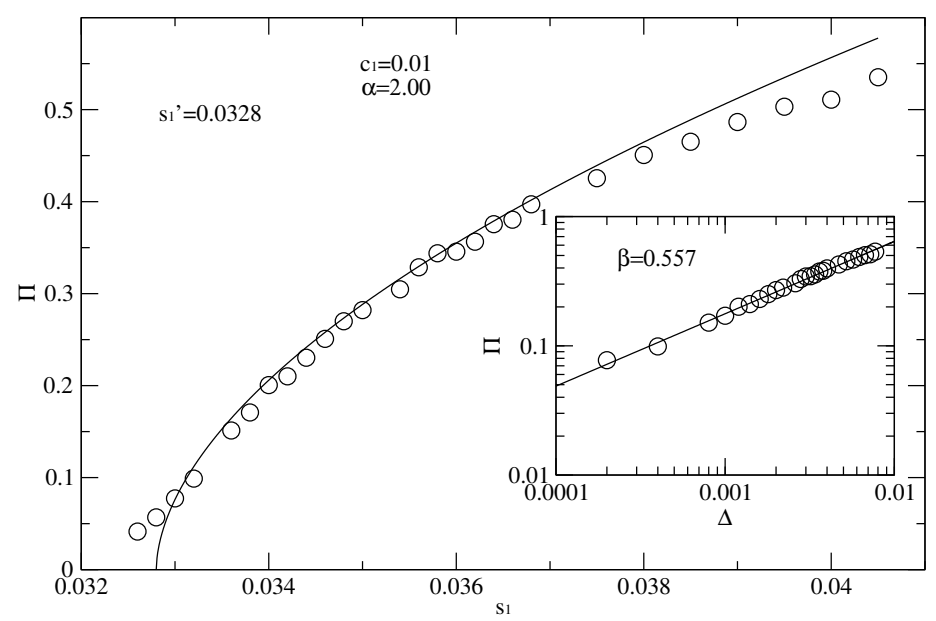

Figura 17: $\Pi$ contra $s_{1}$ e $\Pi$ contra $\Delta-c_{1}=0.01$ e $\alpha=2.00$

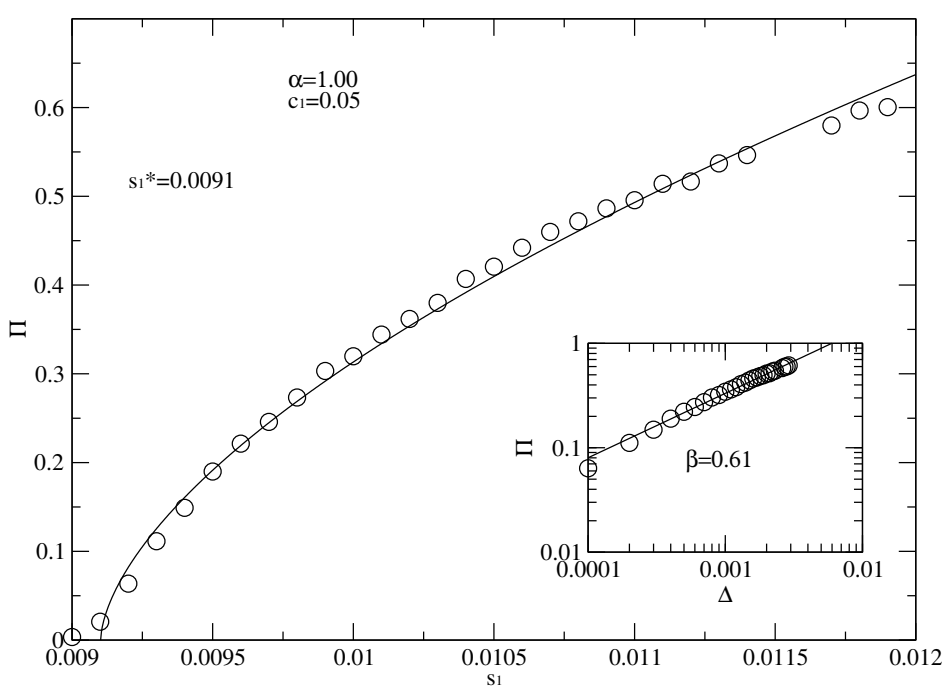

Figura 18: $\Pi$ contra $s_{1}$ e $\Pi$ contra $\Delta-c_{1}=0.05$ e $\alpha=1.00$ 


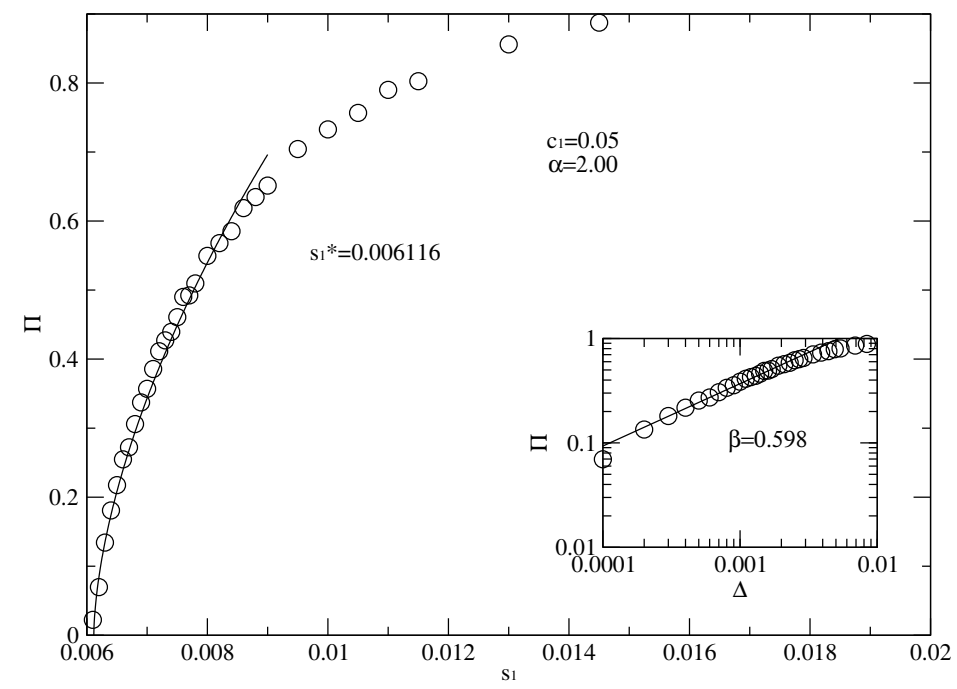

Figura 19: $\Pi$ contra $s_{1}$ e $\Pi$ contra $\Delta-c_{1}=0.05$ e $\alpha=2.00$

\begin{tabular}{|c|c|c|c|c|}
\hline & $\alpha=0.00$ & $\alpha=0.25$ & $\alpha=1.00$ & $\alpha=2.00$ \\
\hline$c_{1}=0.00$ & 0.02085 & 0.0230 & 0.0325 & 0.0665 \\
\hline$c_{1}=0.01$ & 0.02085 & 0.0209 & 0.0231 & 0.0328 \\
\hline$c_{1}=0.05$ & 0.02085 & 0.0135 & 0.0091 & 0.0061 \\
\hline
\end{tabular}

Tabela 3: Valores de $s_{1}^{*}$

\begin{tabular}{|c|c|c|c|c|}
\hline & $\alpha=0.00$ & $\alpha=0.25$ & $\alpha=1.00$ & $\alpha=2.00$ \\
\hline$c_{1}=0.00$ & 0.59 & 0.64 & 0.64 & 0.61 \\
\hline$c_{1}=0.01$ & 0.59 & 0.58 & 0.59 & 0.58 \\
\hline$c_{1}=0.05$ & 0.59 & 0.57 & 0.61 & 0.60 \\
\hline
\end{tabular}

Tabela 4: Valores de $\beta^{\prime}$ nos pontos críticos

Os valores do expoente crítico $\left(\beta^{\prime}\right)$ obtidos nas simulações são relativamente próximos do valor esperado para o expoente numa transição de fase de um sistema com um estado absorvente típico da Percolação Dirigida $\beta^{\prime}=\beta=0.58$, 
conforme tabela 1.

Ainda compusemos dois diagrama de fases, sendo um deles de $s_{1}^{*}$ contra $\alpha$ e o outro de $s_{1}^{*}$ contra $c_{1}$, que mostramos a seguir.

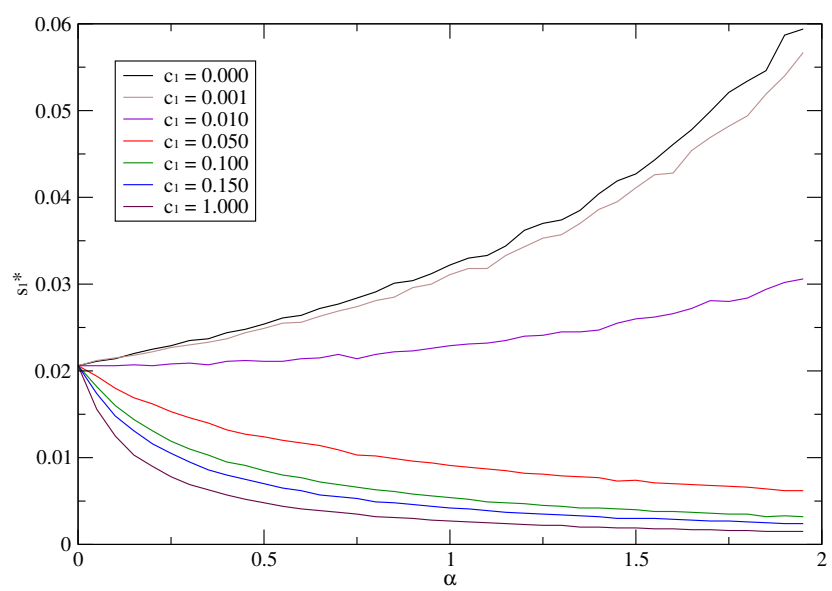

Figura 20: Diagrama de fases $s_{1}^{*} \mathrm{x} \alpha$.

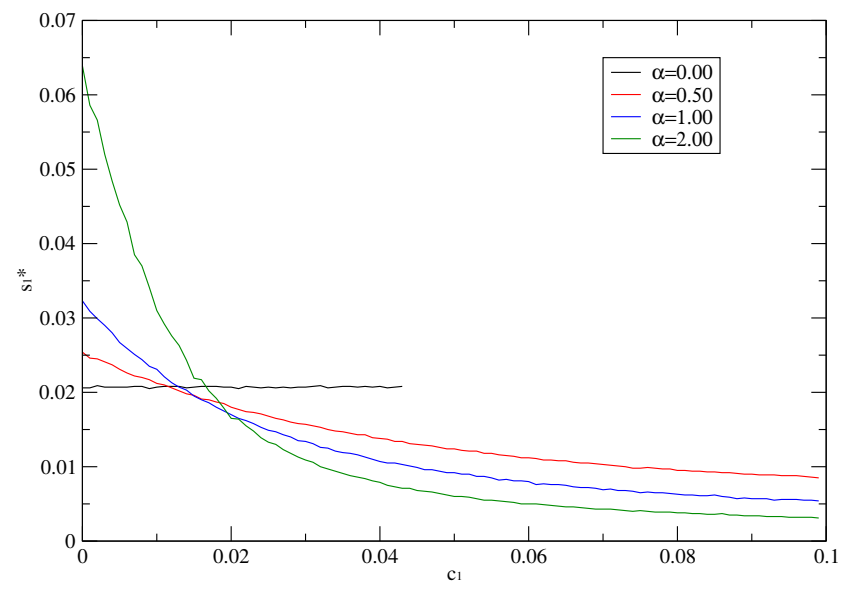

Figura 21: Diagrama de fases $s_{1}^{*}$ x $c_{1}$. 


\subsection{Conclusão}

No gráfico da Figura 20 percebemos que a curva referente aos valores $c_{1}=0.000$ e $c_{1}=0.001$ possuem inclinação positiva. Tal comportamento se deve ao fato de que quanto maior o valor de $\alpha$ maior é a produção da enzima, de modo que esta passa a ocupar mais sítios, dificultando a propagação dos replicadores quando $c_{1}$ é muito pequeno, exigindo assim uma intensidade maior de replicação para que a população sobreviva. Para os valores mais altos de $c_{1}$ (a partir de 0.050) apresentados as curvas possuem inclinação negativa pois quanto maior o valor de $\alpha$, como dissemos, maior é a produção de enzima, e como a enzima auxilia na reprodução do replicador através da catálise com parâmetro $c_{1}$, a intensidade de replicação necessária para a manutenção da população tende a diminuir. Na curva $c_{1}=0.010$ notamos que o crescimento é bastante lento.

Como a catálise somente ocorre com a presença da enzima que só pode ser produzida pelo replicador, conforme equação 25 , não pode haver um regime onde $s_{1}^{*}=0$, de modo que as curvas com inclinação negativa somente se anulam no limite $\alpha \rightarrow \infty$.

No gráfico da Figura 21 percebemos que a curva correspondente a $\alpha=0$ é uma constante em $s_{1}^{*}=0.0208$, o que ocorre porque para tal valor de $\alpha$ não há produção de enzima, de modo que independentemente do valor de $c_{1}$ não existe catálise no sistema. Sendo assim, para qualquer valor de $c_{1}$ o valor crítico de $s_{1}$ será sempre o mesmo. Para as demais curvas, onde $\alpha \neq 0$, percebemos que para valores pequenos de $c_{1}$ o valor crítico de $s_{1}$ aumenta $\operatorname{com} \alpha$, o que ocorre por causa do baixo valor da intensidade de catálise, que acaba não contribuindo para a reprodução dos replicadores de forma significativa e como há produção de enzima, o valor crítico de $s_{1}$ aumenta. Conforme $c_{1}$ aumenta, a produção de enzima passa a colaborar mais com a reprodução por catálise, de modo que com o aumento em $\alpha s_{1}^{*}$ diminui. 
Notamos ainda que as curvas se interceptam em valores entre $c_{1}=0.01$ e $c_{1}=0.02$, o que, associado ao gráfico 20 , nos leva à conclusão de que nas proximidades desses valores o comportamento de $s_{1}^{*}$ é aproximadamente constante, com uma leve inclinação positiva ou negativa que se revela para valores maiores de $\alpha$, como mostra a curva correspondente a $c_{1}=0.010$ no gráfico 20. Esta região, portanto, é aquela onde o benefício gerado pela catálise na reprodução do replicador é equivalente ao prejuízo provocado pela produção da enzima no consumo de espaço na rede.

Pelos valores do expoente crítico $\beta^{\prime}$ obtidos, que são mostrados na tabela 4, podemos concluir que as transições de fase presentes são todas contínuas e pertencentes à classe de universalidade da Percolação Dirigida. 


\title{
4 CRIAÇÃO POR PARES E TRINCAS
}

\author{
CASO BIDIMENSIONAL
}

\subsection{Introdução}

Estudamos, através de simulações numéricas, um modelo de replicação na rede, bidimensional e de dois estados, que exibe uma transição de fases descontínua longe do equilíbrio para um estado absorvente único. As bases da dinâmica do modelo são: a replicação auto catalítica na qual pelo menos $K+1$ replicadores adjacentes são necessários para criar um novo replicador num sitio vizinho vazio; e o decaimento espontâneo. Diferentemente das versões unidimensionais conhecidas como criação por pares $(K=1)$ e por trincas $(K=2)$ que apresentam somente transições contínuas para o estado absorvente, neste modelo encontramos uma transição descontínua para $K=2$ dependendo do valor da probabilidade de replicação. Para $K=0$ e $K=1$ a transição encontrada é contínua e pertence à classe de universalidade da Percolação Dirigida. Através do Processo de Contato Conservativo mostramos que no caso descontínuo a densidade de replicadores apresenta uma dependência não monotônica com a probabilidade de decaimento. Essa análise de estado estacionário é complementada pela análise de espalhamento que nos permite calcular o valor dos expoentes críticos dinâmicos associados ao comportamento assintótico da probabilidade de sobrevivência de uma colônia de replicadores em uma rede infinita.

Neste modelo os estados possíveis dos indivíduos são: 
1. sítio vazio;

2. sítio ocupado.

Os processos de atualização da rede são os seguintes:

- Morte: um sítio ocupado no tempo $t$ passa a estar vazio no tempo $t+1$ com probabilidade $\gamma$;

- Percolação: um sítio vazio no tempo $t$ que possui ao menos um vizinho ocupado que possua, por sua vez, ao menos $k$ primeiros vizinhos ocupados passa a estar ocupado no tempo $t+1$ com probabilidade $1-(1-s)^{n_{o}}$, onde $n_{o}$ é o número de primeiros vizinhos que satisfazem a condição e $s$ é a probabilidade individual de replicação.

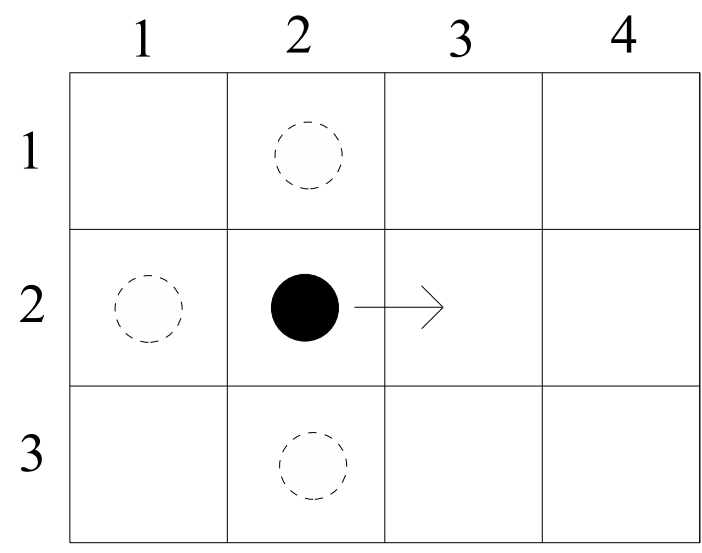

Figura 22: Ilustração das regras de ocupação de um sítio vazio $(2,3)$ pelo replicador $(2,2)$. Uma cópia do replicador ocupa aquele sítio com probabilidade $s \in(0,1]$ se há ao menos $K$ replicadores na soma de $(1,2),(2,1)$ e $(3,2)$

\subsection{Simulações e resultados}

As simulações deste modelo foram executadas de duas formas. Primeiramente consideramos o processo de contato ordinário em uma rede quadrada 
de dimensão linear $L$, povoada com $k+1$ indivíduos na condição inicial. Então iniciamos a dinâmica, promovendo atualizações assíncronas nos sítios. Cada atualização de um sítio corresponde a uma iteração e cada passo de tempo representa um número de iterações aproximadamente igual a quatro vezes o tamanho da população no início daquele passo, o que concluímos que é suficiente para atualizar a rede toda. No regime subcrítico executamos $10^{6}$ tentativas com $10^{4}$ passos de tempo em cada uma. No regime crítico e ao seu redor realizamos $5 \cdot 10^{5}$ tentativas com a mesma variação temporal. Em todas as simulações deste caso $L=200$.

Paralelamente executamos este modelo segundo o processo de contato conservativo, utilizando também uma rede quadrada de dimensão linear $L$. Neste caso a dinâmica é um pouco diferente, pois em cada configuração executa-se uma única tentativa ao longo da qual colhemos as amostras, respeitando intervalos de tempo suficientes para que não haja correlação entre essas amostras. Para cada valor de $N$ executamos um experimento com $10^{5}$ passos de tempo colhendo amostras a cada intervalo de $4 \cdot N$ iterações, medindo $\gamma$, conforme definido na seção 2.3.3.

Em ambas as formas executamos as simulações para $k=0, k=1 \mathrm{e}$ $k=2$, com diversos valores de $s$ em cada caso. O parâmetro de ordem escolhido foi $\gamma$. A partir dos gráficos do processo de contato ordinário extraímos os valores críticos de $\gamma$ bem como os valores dos expoentes críticos $\delta, \eta, z$ e $\nu_{\|}$. Do processo de contato conservativo extraímos os valores de $\beta$.

A seguir apresentamos alguns dos gráficos obtidos.

Os resultados apresentados mostram que quando $k=0$ o sistema apresenta todos os expoentes críticos relativos à classe de universalidade da Percolação Dirigida, conforme a tabela 1 . Para o caso $k=2$ a transição é claramente descontínua e a população no regime crítico não cresce como lei de potência, 

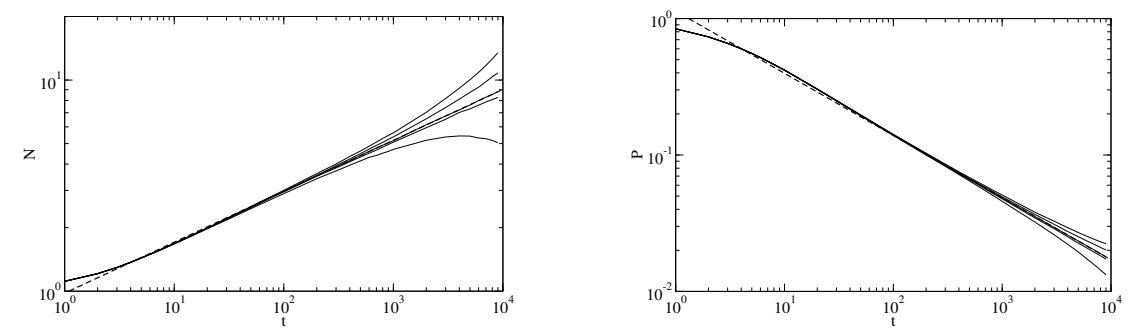

Figura 23: Curvas de $N(t)$ e $P(t)$, no processo de contato ordinário, para $k=0$ e $s=0.1$, com $\gamma=0.239,0.2391,0.23918,0.2392$ e 0.2394 (de cima para baixo). Com esses dados obtivemos $\eta=0.241$ e $\delta=0.455$
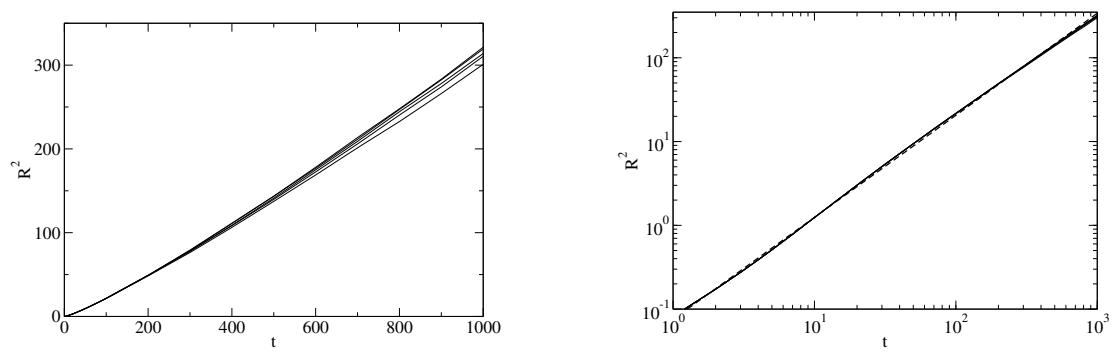

Figura 24: Curvas de $R^{2}(t)$, no processo de contato ordinário, para $k=0$ e $s=0.1$, com $\gamma=0.239,0.2391,0.23918,0.2392$ e 0.2394 (de cima para baixo). Com esses dados obtivemos $z=1.128$. À esquerda em escala linear podemos diferenciar as curvas, o que já não é possível na escala log-log.
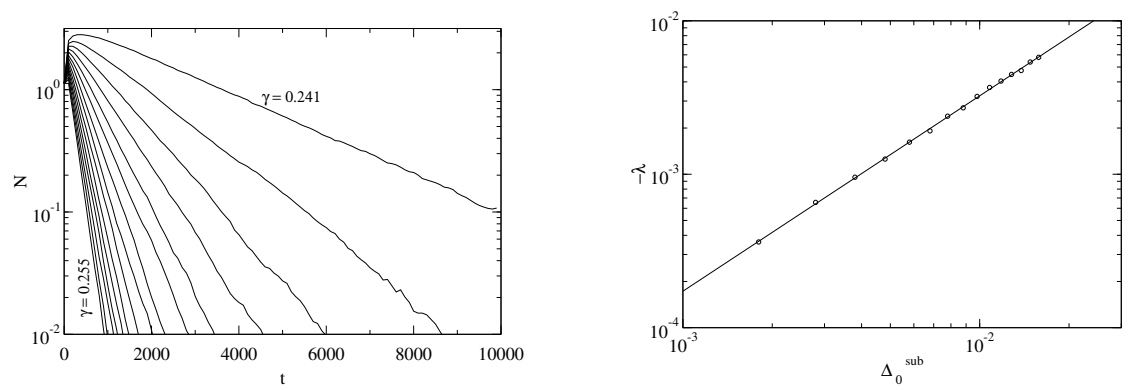

Figura 25: Curvas de $N(t)$, no processo de contato ordinário, para $k=0$ e $s=0.1$, com $\gamma$ entre 0.241 e 0.255 , no intervalo subcrítico (à esquerda) e o gráfico de $-\lambda=-\xi_{\|}$em função da distância em relação ao crítico. Com esses dados obtivemos $\nu_{\|}=1.273$. 

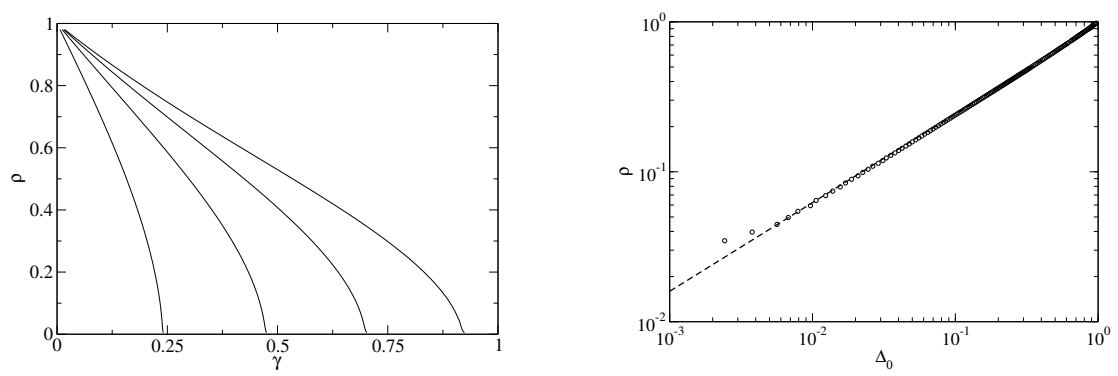

Figura 26: Curvas do processo de contato conservativo para $k=0$. À esquerda o gráfico de $\rho$ contra $\gamma$ para $s=0.1,0.2,0.3$ e 0.4 da esquerda para a direita. À direita o gráfico de $\rho$ contra $\Delta_{0}=\gamma^{*}-\gamma$ para $s=0.1$. Do segundo gráfico obtivemos $\beta=0.587$.
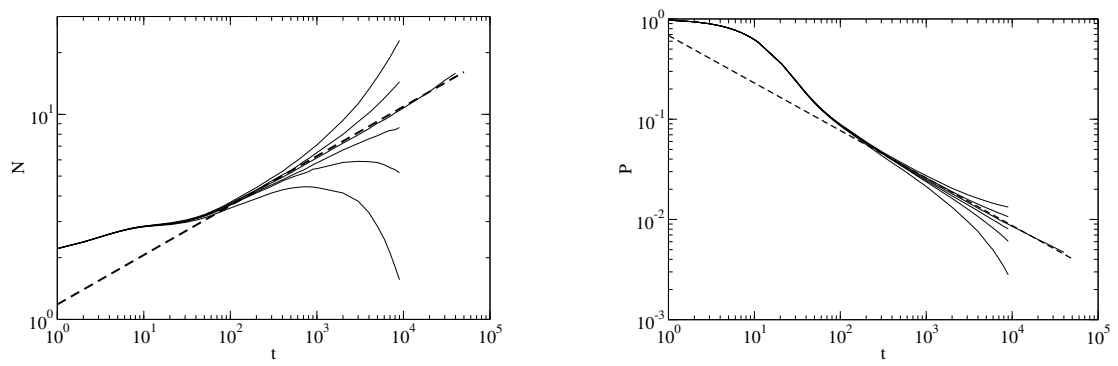

Figura 27: Curvas de $N(t)$ e $P(t)$, no processo de contato ordinário, para $k=1$ e $s=0.1$, com $\gamma=0.1574,0.1575,0.15756,0.1576,0.1577$ e 0.1579 (de cima para baixo). Com esses dados obtivemos $\eta=0.23$ e $\delta=0.47$
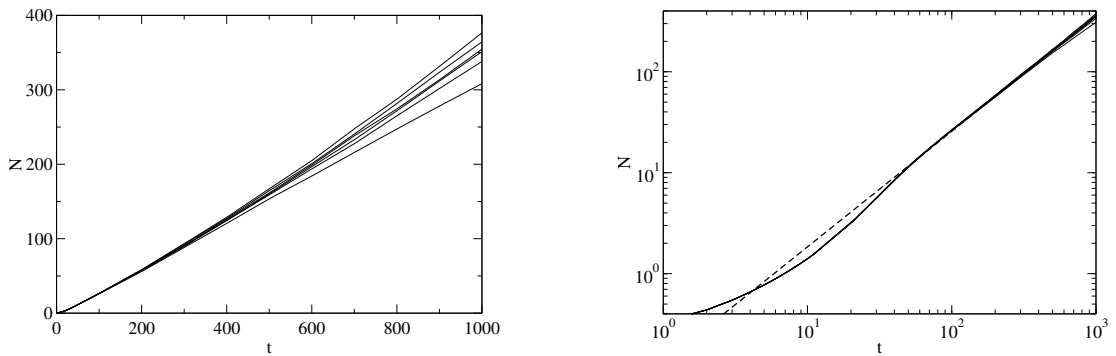

Figura 28: Curvas de $R^{2}(t)$, no processo de contato ordinário, para $k=1$ e $s=0.1$, com $\gamma=$ $0.1574,0.1575,0.15758,0.1576,0.1577$ e 0.1579 (de cima para baixo). Com esses dados obtivemos $z=1.144$. 

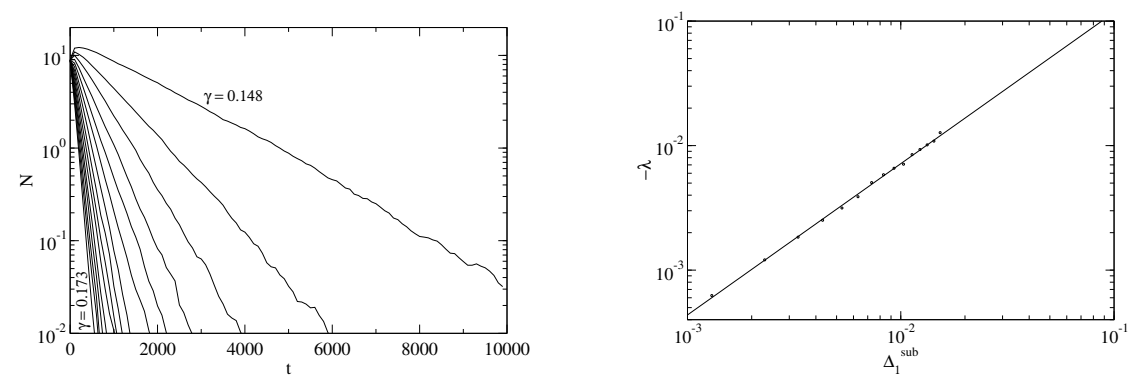

Figura 29: Curvas de $N(t)$, no processo de contato ordinário, para $k=1$ e $s=0.1$, com $\gamma$ entre 0.148 e 0.173 , no regime subcrítico (à esquerda) e o gráfico de $-\lambda=-\xi_{\|}$em função da distância em relação ao crítico. Com esses dados obtivemos $\nu_{\|}=1.215$.
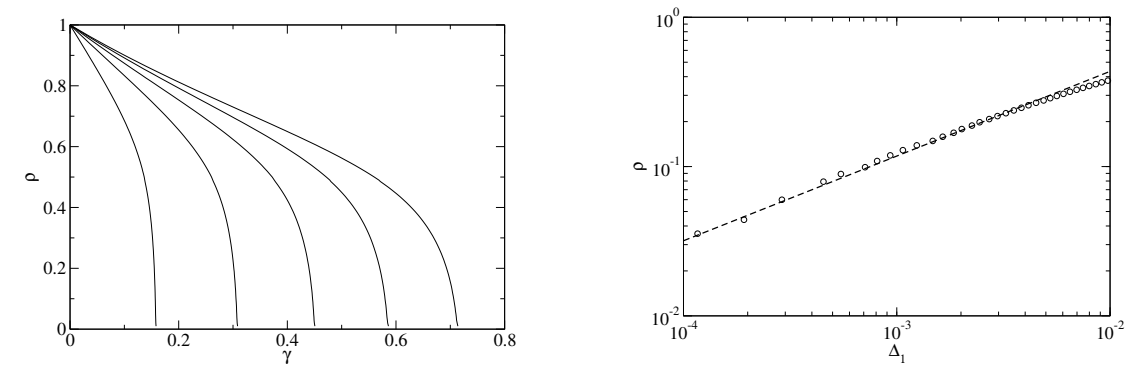

Figura 30: Curvas do processo de contato conservativo para $k=1$. À esquerda o gráfico de $\rho$ contra $\gamma$ para $s=0.1,0.2,0.3,0.4$ e 0.5 da esquerda para a direita. À direita o gráfico de $\rho$ contra $\Delta_{1}$ para $s=0.1$. Do segundo gráfico obtivemos $\beta=0.57$.
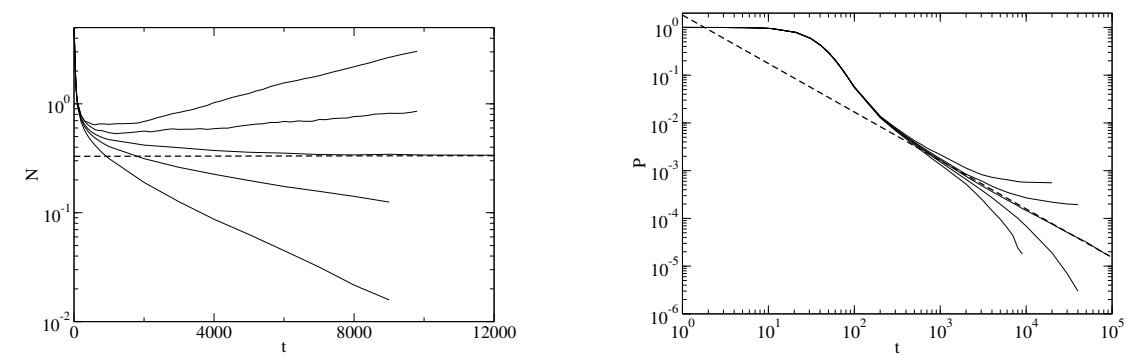

Figura 31: Curvas de $N(t)$ e $P(t)$, no processo de contato ordinário, para $k=2$ e $s=0.1$, com $\gamma=0.0725,0.0726,0.072645,0.0727$ e 0.0728 (de cima para baixo). Com esses dados obtivemos $\eta=0.0$ e $\delta=1.01$. 

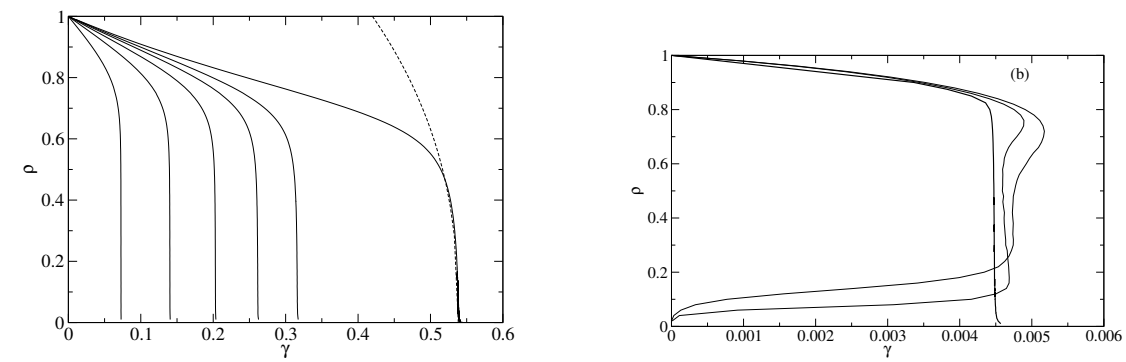

Figura 32: Curvas do processo de contato conservativo para $k=2$. À esquerda o gráfico de $\rho$ contra $\gamma$ para $s=0.1,0.2,0.3,0.4,0.5$ e 1.0 da esquerda para a direita.A linha pontilhada é uma lei de potência com expoente 0.41. À direita o gráfico de $\rho$ contra $\gamma$ para $s=0.1$ e $L=201,101,51,21,11,7$ e 5. Na inserção uma comparação dos dados obtidos no processo de contato ordinário (linha segmentada) com os obtidos pelo processo de contato conservativo com $L=11$ (linha cheia).
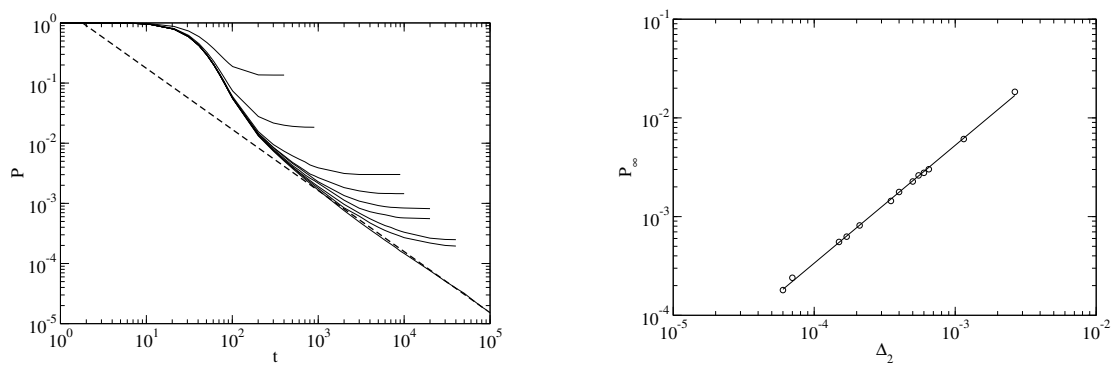

Figura 33: Análise de espalhamento para $K=2, s=0.1$ na região super crítica. Esquerda: gráfico log-log de $P(t)$ evidenciando os valores de saturação $P_{\infty}$. Os valores de $\gamma$ são $0.06,0.07$, 0.072, 0.0723, 0.07244, 0.07250, 0.07258 e 0.07259 de cima para baixo. Direita: gráfico log-log de $P_{\infty}\left(\gamma-\gamma^{*}\right)$. A inclinação da linha cheia é $\beta^{\prime}=1.16 \pm 0.09$. 

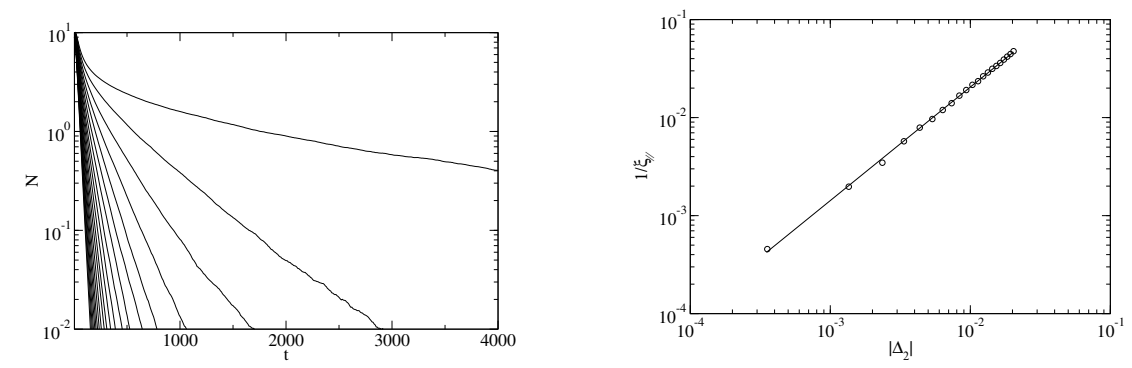

Figura 34: Análise de espalhamento para $K=2, s=0.1$ na região sub crítica. Esquerda: gráfico monolog de $N(t)$. A inclinação de cada linha representa o expoente $1 / \xi_{\|}$do decaimento exponencial da população neste regime. Os valores de $\gamma$ variam entre 0.074 e 0.0728 com passo -0.0001 da esquerda para a direita. Direita: gráfico $\log -\log$ de $1 / \xi_{\|}$em função de $\left|\gamma-\gamma^{*}\right|$. A inclinação da linha cheia é $\nu_{\|}=1.1 \pm 0.1$.
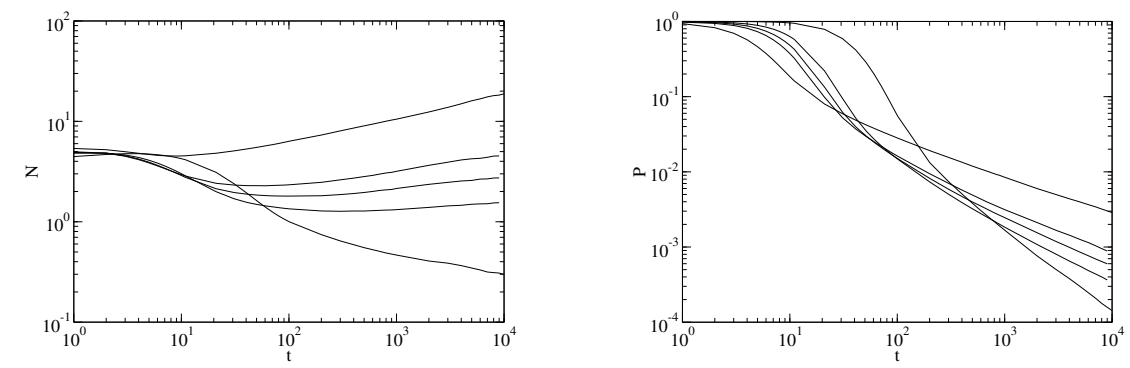

Figura 35: Análise de espalhamento para $K=2, s=0.1,0.3,0.4,0.5$ e 1 de baixo para cima. Esquerda: gráfico log-log de $N(t)$. Direita: gráfico log-log de $P(t)$. A mudança nas inclinações indicam alteração no comportamento crítico. Neste caso a transição muda de descontínua para contínua quando $s$ é superior a 0.3 . 
permanecendo num patamar constante em vez disso. Para o caso $k=1$ a transição é contínua, embora os expoentes críticos não possuam a mesma precisão do caso $k=0$. Dessa forma os casos $k=0$ e $k=1$ podem ser classificados com pertencentes à classe de universalidade da Percolação Dirigida.

Além disso encontramos as expressões dos valores críticos de $\gamma$ em função de $s$ através de ajuste numérico dos valores críticos obtidos para diversos valores de $k$ e $s$. As expressões encontradas foram:

$$
\gamma_{0}^{*}=2.42517 \cdot s-0.333302 \cdot s^{2}
$$

$$
\gamma_{1}^{*}=1.61457 \cdot s-0.390175 \cdot s^{2}
$$

$$
\gamma_{2}^{*}=0.7473439 \cdot s-0.208939 \cdot s^{2}
$$

e um gráfico comparativo entre essas curvas foi montado e é apresentado na Figura 4.2 , onde fica evidente que os valores críticos de $\gamma$ ficam menores com o aumento em $k$. 


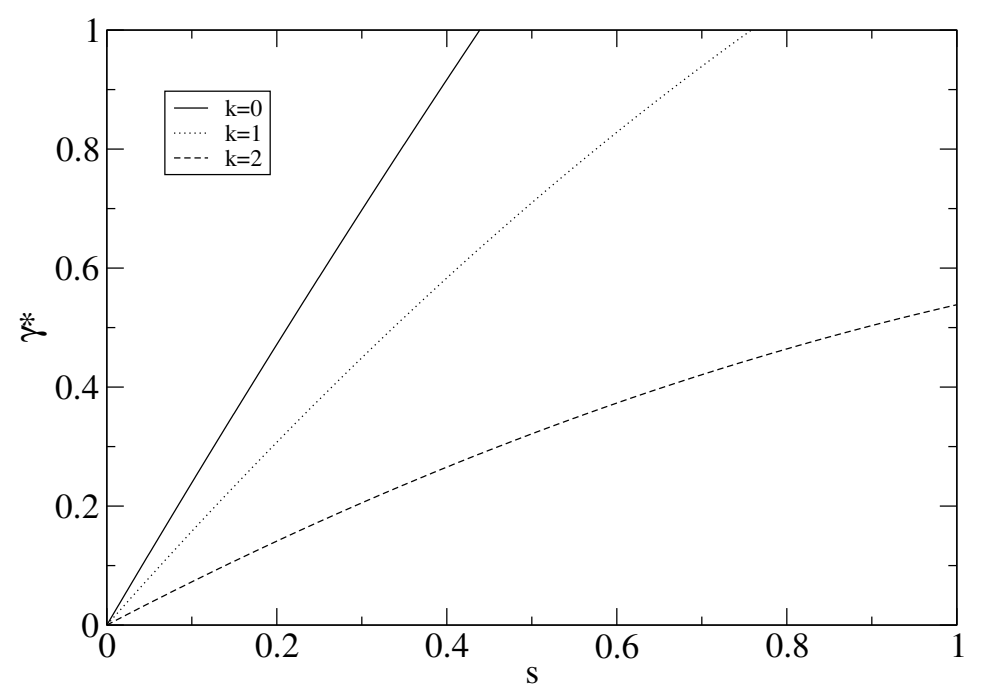

Figura 36: Comparação entre os valores críticos de $\gamma$ em função de s para $k=0,1$ e 2 .

\subsection{Conclusão}

Para os casos $k=0$ e $k=1$ há apenas transições de fase contínuas para estados absorventes únicos, independentemente dos parâmetros. Essas transições pertencem à classe de universalidade da Percolação Dirigida. Os resultados para $k=0$ são indiscutíveis enquanto que para $k=1$ há uma precisão menor no cálculo dos expoentes críticos. Mesmo assim todos os resultados estão coerentes com a teoria estabelecida para transições de fase contínuas.

O processo de contato conservativo mostra um comportamento não monotônico para o caso $k=2$ para $s$ pequeno, indicando, conjuntamente com a análise de espalhamento, onde $N(t)$ no regime crítico tende a uma constante, uma transição descontínua. Porém essa transição apresenta algumas características de transições contínuas, pois o comprimento de correlação temporal diverge como lei de potência com expoente $\nu_{\|} \approx 1$, assim como a probabilidade de sobrevivência $P(t)$ com expoente $\delta \approx 1$ e de $P_{\infty}$ com expoente $\beta^{\prime} \approx 1$.

Aumentando o valor de $s$ temos evidências de que a transição se 
torna contínua (para $s>0.3$ ) e portanto pertencente à classe de universalidade da Percolação Dirigida, porém os valores dos expoentes críticos apresentam uma variação contínua em $s$. 


\section{CRIAÇÃO POR TRINCAS}

\section{CASO DIFUSIVO UNIDIMENSIONAL}

Estudamos aqui o modelo unidimensional de criação por trincas de Dickman e Tomé [9] no qual a condição necessária para a replicação é a presença de pelo menos três replicadores ocupando posições consecutivas na vizinhança de um sítio vazio. Decaimento e difusão de um replicador para um sítio vizinho também são levados em conta. A motivação para a criação deste modelo é a busca pelo modelo mais simples de não equilíbrio, com interações locais, que apresente uma transição de fase descontínua para um estado absorvente [9].

Na ausência de difusão o modelo de criação por trincas exibe uma transição contínua para o estado absorvente único, correspondente à rede completamente vazia. Essa transição pertence à classe de universalidade da percolação dirigida. Quando a difusão ocorre, entretanto, a transição muda de comportamento. A análise original de Dickman e Tomé indica que a transição contínua associada a regimes de baixa difusão torna-se descontínua para difusão suficientemente alta. Essa conclusão é questionada por Hinrichsen [54], que apresenta argumentos gerais contra a existência de transições descontínuas em certas classes de modelos unidimensionais irreversíveis e fornece evidências numéricas, obtidas através da análise de espalhamento, de que a transição no modelo de criação por trincas é sempre contínua e pertencente à classe de universalidade da percolação dirigida, independentemente da intensidade de difusão. Mais recentemente Fiore e Oliveira [55] utilizaram o processo de contato conservativo difusivo para reafirmar os resultados obtidos por 
Dickman e Tomé.

Aqui investigamos a transição do modelo de criação por trincas utilizando tanto a análise de espalhamento como o processo de contato conservativo difusivo e encontramos fortes evidências de uma transição descontínua para o regime de alto grau de difusão, mas com variação contínua dos valores dos expoentes críticos entre os da percolação dirigida e da percolação dirigida compacta á medida que a intensidade de difusão aumenta.

Neste modelo utilizamos uma rede unidimensional de dois estados, ocupado ou vazio. Os processos de atualização do autômato são os seguintes:

- Difusão: O processo de difuão ocorre com uma probabilidade $D$. Nele um sítio $i$ ocupado é escolhido aleatoriamente, assim como um dos seus sítios primeiros vizinhos, $k=i \pm 1$. Se $k$ estiver vazio, a partícula em $i$ se move para $k$;

- Criação: O processo de criação ocorre com probabilidade

$$
c \equiv \frac{(1-D) \lambda}{1+\lambda}
$$

onde um sítio ocupado $i$ é escolhido aleatoriamente. Se seus primeiros vizinhos, $i+1$ e $i-1$ estiverem ocupados, então escolhe-se um, $k$ entre os dois primeiros vizinhos da trinca, $i-2$ e $i+2$, aleatoriamente. Se $k$ estiver vazio, uma nova partícula é criada e passa a ocupar tal sítio, caso contrário nada acontece;

- Decaimento:O processo de decaimento ocorre com probabilidade

$$
\gamma \equiv \frac{(1-D)}{1+\lambda}
$$


onde um sítio ocupado é escolhido aleatoriamente e tem seu estado alterado para vazio.

Existe um estado absorvente no modelo, que é aquele no qual todos os sítios estão desocupados, e uma transição de fase para este estado que pode ser contínua ou descontínua dependendo dos parâmetros associados a cada um dos processos descritos anteriormente.

\subsection{Análise de Espalhamento}

Foi feito um estudo do espalhamento onde foram executadas simulações com $D=0, D=0.95$ e $D=0.98$, localizando-se os valores críticos de $\lambda$ em todos os casos. Em cada geração foi calculado o número médio de indivíduos $N(t)$ e a probabilidade de sobrevivência $P(t)$ e a partir dessas grandezas foi possível caracterizar as transições de fase de acordo com os expoentes $\eta, \delta$ e $z$. As Figuras 37 a 39 apresenta as curvas críticas bem como os expoentes dinâmicos associados. Em cada caso $t_{\max }$ foi escolhido convenientemente.

Como pode ser visto na Figura 37 para a situação em que $D=0$ os expoentes críticos são os mesmos da Percolação Dirigida, de acordo com os valores apresentados na tabela 1 .

Já no caso em que $D=0.98$ os expoentes críticos obtidos são aqueles associados a uma transição de fase descontínua pertencentes à classe de universalidade da Percolação Dirigida Compacta. No caso $D=0.95$ embora os expoentes críticos obtidos (Figura 38) não sejam aqueles da Percolação Dirigida, acreditamos que evidenciem uma transição de fase contínua. 


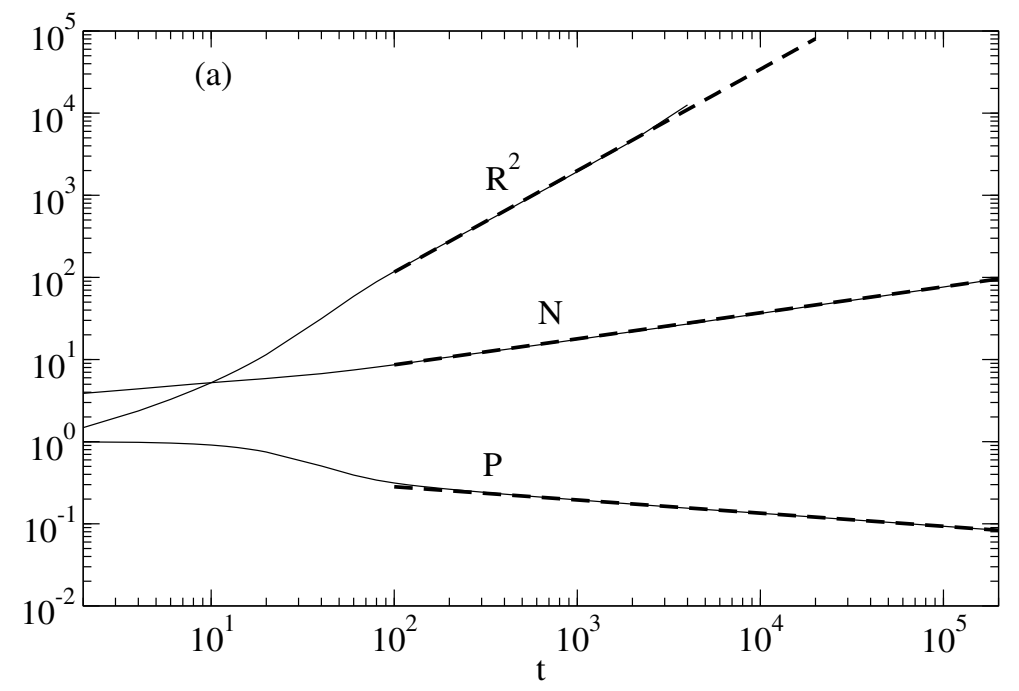

Figura 37: Análise de espalhamento com $D=0$. O valor crítico de $\lambda$ é 12.015 e os valores dos expoentes críticos $\eta, \delta$ e $z$ são $0.316,0.160$ e 1.27 respectivamente.

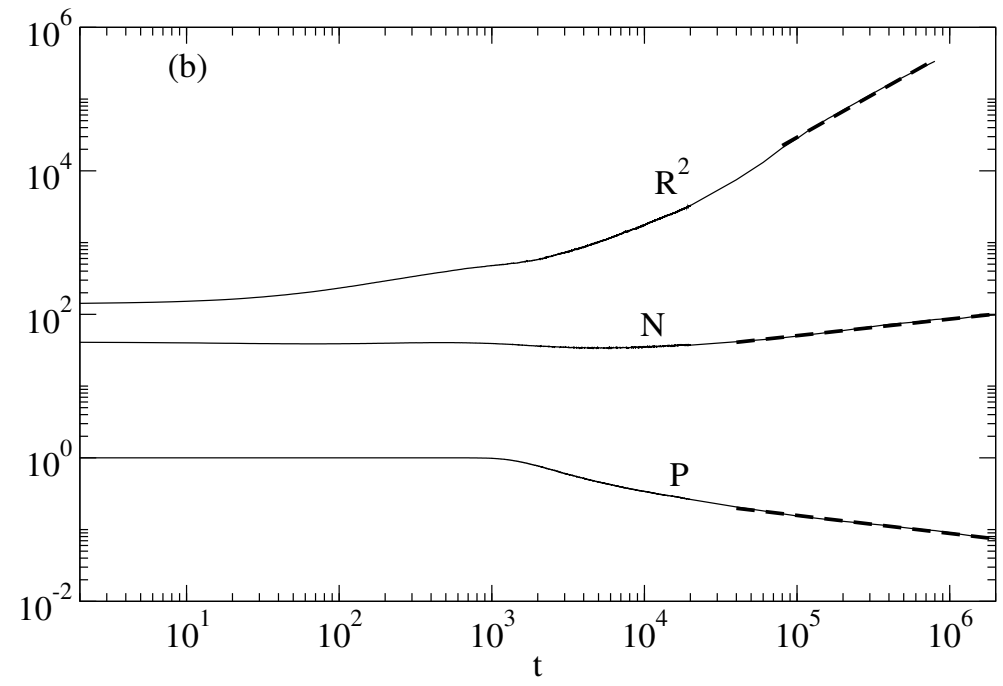

Figura 38: Análise de espalhamento com $D=0.95$. Valor crítico de $\lambda$ é 10.11 e os expoentes críticos $\eta, \delta$ e $z$ iguais a $0.24,0.25$ e 1.15 respectivamente. 


\section{CRIAÇÃO POR TRINCAS 5.2 Processo de Contato Conservativo Difusivo}

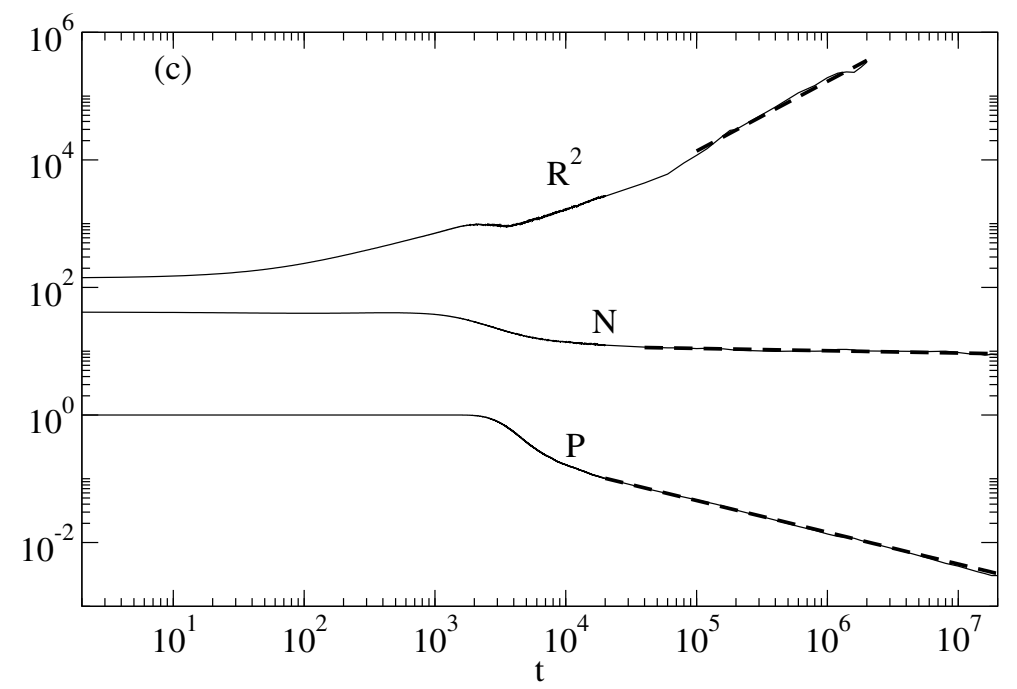

Figura 39: Análise de espalhamento com $D=0.98$. Valor crítico de $\lambda$ é 9.6 e os expoentes críticos $\eta, \delta$ e $z$ iguais a $-0.003,0.5$ e 1.09 respectivamente.

\subsection{Processo de Contato Conservativo Difusivo}

Além da análise de espalhamento, também foi realizado um estudo utilizando o processo de contato conservativo. Neste caso a execução da dinâmica do problema é um pouco alterada. Inicialmente uma partícula é escolhida e um número aleatório gerado uniformemente entre 0 e 1 . Se esse número aleatório for menor do que $D$ ocorre difusão da partícula para um lado escolhido aleatoriamente. Caso contrário, verifica-se os sítios vizinhos da partícula, se ambos estiverem ocupados uma trinca é formada, se não, nada ocorre e escolhe-se nova partícula. Quando uma trinca é encontrada escolhe-se aleatoriamente um dos sítios seus vizinhos. Se tal sítio estiver vazio, uma partícula qualquer da rede é escolhida aleatoriamente e é colocada nesse sítio, mas se estiver ocupado, nada ocorre e retorna-se o passo inicial. As atualizações na rede são assíncronas e uma geração é definida como a sucessão de $n$ atualizações onde n é o número de partículas na rede.

Em cada geração foi calculada uma grandeza chamada $\alpha$, definida como o número total de sítios ativos divididos por $2 \cdot N$, onde sítio ativo é aquele que está na vizinhança imediata de uma trinca. A grandeza $\alpha$ se relaciona com $\gamma$ da forma 


\section{CRIAÇÃO POR TRINCAS 5.2 Processo de Contato Conservativo Difusivo}

explicitada pela equação 32. Ao final de $t_{\max }$ gerações é obtido o valor médio de $\alpha$ em função de $\rho=n / N$, que é a densidade de partículas na rede. As Figuras 40 a 42 ilustram os resultados das simulações do processo de contato conservativo.

$$
\gamma=\alpha \frac{1-D}{1+\alpha}
$$
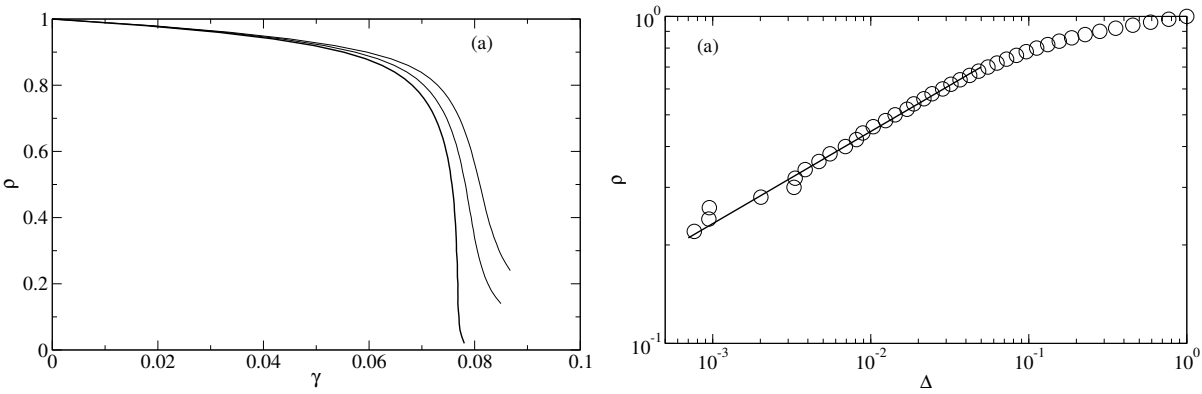

Figura 40: Processo de contato conservativo, com $D=0$. À esquerda curvas de $\rho$ em função de $\alpha^{\prime}$, com $L=100,200$ e 10000 da mais externa para a mais interna. À direita gráfico log-log de $\rho$ contra $\Delta=\gamma-\gamma^{*}$, onde $\gamma^{*}=0.0768$. O expoente crítico $\beta$ foi estimado em 0.271 .
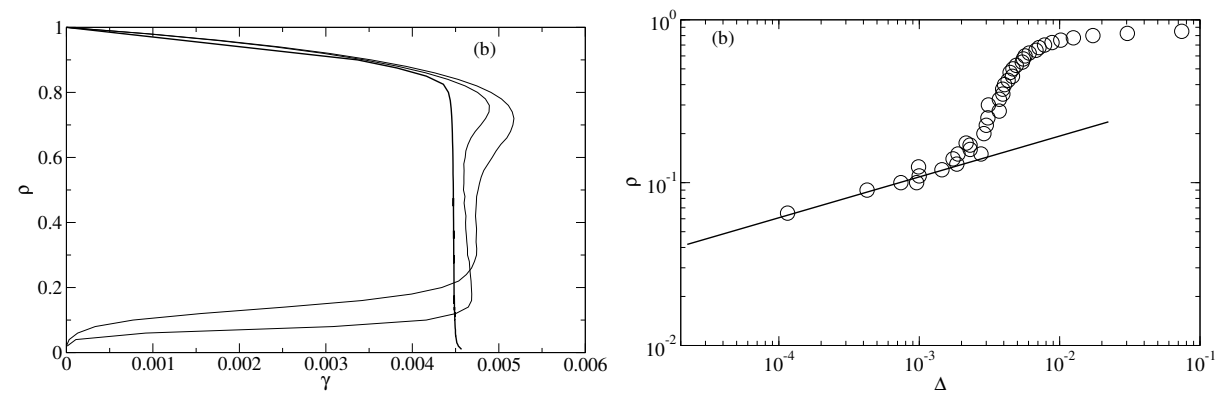

Figura 41: Processo de contato conservativo, com $D=0.95$. À esquerda curvas de $\rho$ em função de $\alpha^{\prime}$, com $L=100,200$ e 10000 da mais externa para a mais interna.À direita gráfico log-log de $\rho$ contra $\Delta$, onde $\gamma^{*}=0.00449$. O expoente crítico $\beta$ foi estimado em 0.251. 

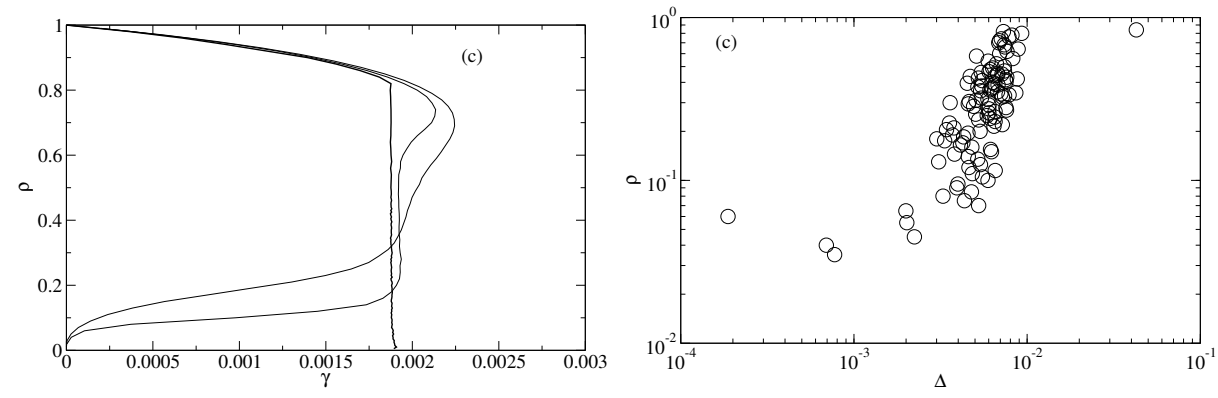

Figura 42: Processo de contato conservativo, com $D=0.98$. À esquerda curvas de $\rho$ em função de $\alpha^{\prime}$, com $L=100,200$, e 10000 da mais externa para a mais interna. À direita gráfico log-log de $\rho$ contra $\Delta$, onde $\gamma^{*}=0.00189$.

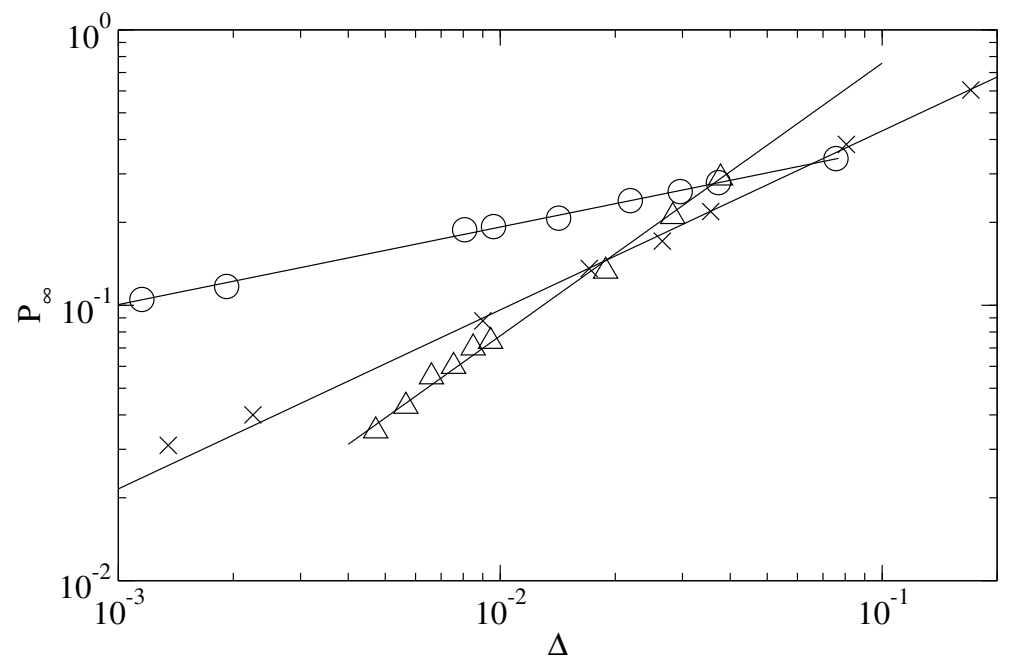

Figura 43: $P_{\infty}$ em função de $\Delta$ para $D=0.0,0.95$ e 0.98 . Os expoentes $\beta^{\prime}$ associados são: $0.282(6)$ para $D=0.0,0.65(1)$ para $D=0.95$ e $0.98(5)$ para $D=0.98$. 


\subsection{Conclusão}

Os resultados mostram que, assim como no trabalho original de Dickman e Tome [9], existe uma transição descontínua para regimes de alto grau de difusão. Essa transição, no caso, se evidencia pela presença de comportamentos em lei de potência com expoentes característicos da Percolação Dirigida Compacta. Notamos que para o caso em que $D=0.98$ os expoentes encontrados são mais próximos daqueles correspondentes à Percolação Dirigida Compacta do que no caso $D=0.95$, sendo que para $D=0.9$ os expoentes são os mesmos da Percolação Dirigida, o que indica uma transição contínua dos expoentes críticos entre essas duas classes de universalidade à medida que o parâmetro difusivo $D$ aumenta. É de se esperar, no entanto, que haja um comportamento transiente nessa transição, onde dependendo dos parâmetros de execução do modelo (tempo de execução, tamanho da população, etc.) sejam obtidos os expoentes críticos hora de uma classe, hora de outra. 


\section{OS NÚMEROS PRIMOS E A COMPETIÇÃO}

\subsection{Introdução}

Os insetos que possuem ciclos de vida longos e bem definidos são objetos raros na natureza e seu estudo já vem sendo feito desde o final do século XIX $[13,15,19,56-58]$, mas entre esses insetos fascinantes alguns chamam mais a atenção da comunidade científica: as cigarras do gênero Magicicada que vivem na América do Norte. Seu ciclo de vida se inicia quando os adultos se acasalam e as fêmeas botam seus ovos no solo próximo das árvores. Num intervalo de alguns dias a poucas semanas esses ovos eclodem liberando as larvas que se enterram até atingirem as raízes das quais extraem a seiva que irá sustentá-las durante seu período de diapausa. Assim elas permanecem durante vários anos (13 ou 17, no caso das espécies norteamericanas) emergindo com um sincronismo impressionante ao final desse estágio, durante a primavera. Durante a emergência, onde milhares de indivíduos adultos saem do solo no intervalo de uma ou duas semanas, ocorre novo acasalamento e cada fêmea botará em torno de 400 a 600 ovos, iniciando novo ciclo $[56]$.

Existem evidências de que essas cigarras possuem um mecanismo preciso de contagem do tempo vinculado às variações da quantidade de seiva no xilema [59]. Tais evidências ajudam a esclarecer como esses insetos conseguem emergir com tamanho sincronismo, mas não são suficientes para elucidar as origens desse comportamento, do fato de emergirem somente a cada 13 ou 17 anos, sendo os ciclos de vida mais longos entre todos os insetos, e por que seus ciclos duram 
números primos de anos.

Várias propostas foram apresentadas, com base em modelos teóri$\cos [13,15,17,18,20,60,61]$ e estudos ambientais [14, 16, 21, 22, 25, 26, 56, 59, 62-64], mas todas elas podem ser colocadas em duas vertentes principais: a primeira que atribui a origem dos ciclos longos, primos e com sincronismo à predação e parasitismo, e a segunda que acredita numa origem provocada pela competição interespecífica entre as próprias cigarras com diferentes ciclos de vida.

Como defensores da primeira vertente Lloyd e Dybas [13] acreditam que o alongamento dos ciclos, assim como sua convergência para valores primos, foi provocado principalmente pela presença de supostos parasitóides de ciclos longos, e que o sincronismo teria se fixado na população por causa da vantagem que ele proporciona frente ao ataque dos predadores durante a emergência em comparação com espécies que emergem anualmente. Embora no artigo de Lloyd e Dibas a ocorrência dos ciclos primos somente se dê mediante uma configuração muito restrita dos parâmetros, May [14] lembra que apenas $0,2 \%$ das espécies catalogadas de cigarras apresentam esse tipo de comportamento na natureza.

Hoppensteadt e Keller [15] propõem a limitação dos recursos alimentares para as larvas e também o ataque dos predadores na época da emergência.

Mais recentemente Williams et. al. [16] mostra que a emergência explosiva, que é resultado direto do sincronismo entre as cigarras, é uma estratégia de saciação dos predadores aéreos durante o período de reprodução de aproximadamente 4 semanas.

Com base nos artigos de Lloyd e Dybas, May, Hoppensteadt e Keller, Goles [17, 18], e Butler [19], entre outros, Campos et al [20] propõem um modelo 
simples, com poucos parâmetros, através de um autômato celular, onde os ciclos primos surgem como estratégias evolucionárias vencedoras num ambiente onde as presas são consumidas por predadores, de ciclos de vida relativamente longos, somente durante a emergência.

Como defensores da segunda vertente, Cox e Carlton [22-24], seguidos por Yoshimura [25], identificam uma desvantagem seletiva para as espécies de cigarras que hibridizam as suas populações, emergindo juntamente com espeécies de ciclos diferentes dos seus, de modo que entre as espécies de ciclo, por exemplo entre 12 e 15 anos, aquela de ciclo de 13 anos terá realizado mais interações intraespecíficas do que interespecíficas, preservando seu material genético com mais eficiência do que as outras espécies de cigarras cíclicas da sua região, proporcionando um aumento em sua população e ao mesmo tempo o sincronismo em sua emergência. Deste modo as cigarras que possuem ciclos primos possuem vantagem seletiva num ambiente de competição e por isso os ciclos primos se fixaram.

A origem dos ciclos primos ainda é um mistério, mas Grant [21], com base nos artigos de Williams e Simon [26, 27], sugere, a partir de estudos filogenéticos do DNA mitocondrial das diversas espécies de cigarras do gênero, que o alongamento dos ciclos ocorreu há mais de 3 milhões de anos com um ancestral comum, antes da diversificação nas espécies atuais, que acabaram se beneficiando da vantagem seletiva dos ciclos primos.

Neste trabalho apresentamos um modelos simples, baseados em um autômato celular estocástico, semelhante ao apresentado por Campos et al, mas onde somente existem interações competitivas entre presas (não há predadores na rede). A partir dos resultados mostramos que para a emergência de ciclos primos como estratégias evolutivas vencedoras na população é necessária a competição entre as presas de diferentes ciclos, sendo desnecessária a predação. 


\subsection{O Modelo}

O modelo é baseado num autômato celular bidimensional quadrado de dimensão linear $L$. Neste estudo estudo todos os sítios são atualizados simultaneamente, após a varredura em toda a rede. A cada atualização completa da rede o tempo $t$ é incrementado em uma unidade, que chamamos geração. Cada sítio, num instante $t$ pode estar vazio $\left(s_{i}(t)=0\right)$ ou ocupado $\left(s_{i}(t)=1\right)$. Além disso, a cada sítio está associada uma idade instantânea $t_{i}(t)$ e uma estratégia $T_{i}$, sendo ambas números inteiros positivos. Toda vez que $t_{i}(t)=T_{i}$ para um dado sítio $i$ que esteja ocupado, dizemos que ele está ativo, sendo que para todos os outros casos o sítio ocupado é considerado inativo.

A dinâmica do modelo é construída da seguinte maneira: inicialmente uma fração $x_{0}$ da rede é ocupada aleatoriamente. A cada sítio ocupado é dada uma estratégia $T_{i}$ sorteada aleatoriamente a partir de uma distribuição uniforme entre 2 e $T_{\max }$. A idade instantânea inicial de cada sítio $i$ ocupado também é escolhida aleatoriamente, a partir de uma distribuição uniforme entre 0 e $T_{i}$. Para os sítios vazios $t_{i}(t)$ e $T_{i}$ são feitos nulos.

Após a inicialização da rede, varremos os sítios um por um. Quando um sítio, $i$ por exemplo, está vazio, observamos a sua vizinhança de Moore e contamos o número de vizinhos ativos $n_{i}$. Se $n_{i}$ for maior do que um certo limiar $k$, escolhemos aleatoriamente um desses vizinhos ativos, $j$ por exemplo, e promovemos a sua reprodução, criando um descendente que herda a estratégia $T_{j}$ que passará a ocupar o sítio $i$ na geração seguinte, sendo que sua idade momentânea inicial é nula $\left(t_{i}(t+1)=0\right)$. Se o sítio $i$ estiver ocupado, verificamos se está ativo. Caso não esteja a única alteração é o incremento de uma unidade em sua idade momentânea $\left(t_{i}(t+1)=t_{i}(t)+1\right)$. Se estiver ativo, passará a ser ocupado por um 
descendente do indivíduo que o ocupa na geração seguinte com uma probabilidade $(1-\mu)$. O descendente herda a estratégia e tem a idade momentânea zerada. Caso a probabilidade de reposição $(1-\mu)$ não seja satisfeita, o sítio $i$ passa a ser vazio na geração seguinte, com $T_{i}=0$ e $t_{i}(t+1)=0$. Todos os sítios são atualizados ao final da varredura.

Em cada geração contamos o número de indivíduos, ativos ou não, na rede e o número de indivíduos com cada estratégia presente. A estratégia com o maior número de indivíduos na rede em determinada geração é considerada a estratégia vencedora na população naquela geração. A partir do momento em que a população se estabiliza e a estratégia vencedora não mais se altera, dizemos que aquela estratégia é a vencedora da população na amostra como um todo.

\subsection{Resultados}

Nas simulações utilizamos $t_{\max }=10^{7}$, o que mostrou ser um tempo suficiente para a estabilização da população e da sua estratégia vencedora, e $T_{\max }=25$. Fizemos inicialmente $\mu=0$ e depois $\mu=10^{-3}$ e comparamos os resultados para $k=2,3$ e 4 . Também variamos as densidades iniciais $x_{o}$ de ocupação da rede. Nos gráficos das Figuras 44 a 48 a disposição dos itens é:(a) Evolução temporal da estratégia vencedora na população ao longo de uma amostra;(b) Evolução temporal da fração de sítios ocupados na rede;(c) Distribuição das estratégias na população ao final de uma amostra; (d) Histograma das estratégias vencedoras ao final de mil amostras.

A partir das Figuras 44 e 45 notamos que os histogramas das estratégias vencedoras na população ao final de um certo número de amostras são qualitativamente idênticos, porém a convergência da estratégia vencedora em uma amostra é muito mais rápida no caso da Figura 44, onde $\mu=0$. Tais efeitos 
foram observados para outras configurações dos parâmetros $k$ e $x_{0}$ (dados não apresentados).

Nos casos em que $k=2$ notamos que as estratégias mais curtas são as maiores vencedoras nas amostras. Com $k=2$, cada sítio vazio precisa de apenas dois vizinhos ativos em determinada geração para que se torne ocupado na geração seguinte. Sendo assim aqueles indivíduos de ciclo mais curto, que estão ativos muito mais vezes do que os seus competidores, se beneficiam da baixa concorrência para povoar toda a rede, uma vez que a "hibridização"das estratégias é mantida baixa e mais comum entre estratégias curtas.

Diferentemente, nos casos em que $k=3$ (Figura 47) percebemos a superioridade estratégica dos ciclos primos. O valor de $k$ é uma medida da intensidade de competição e quanto maior seu valor, maior o número mínimo de indivíduos que disputam um espaço vazio para seus descendentes. A vantagem dos ciclos curtos já não ocorre neste caso porque a densidade populacional inicial de cada estratégia é muito baixa para evitar a dispersão que ocorre a vez que no mínimo 3 indivíduos ativos são encontrados na vizinhança de um sítio vazio. Neste panorama os ciclos primos passam a ter vantagem, pois como os ciclos curtos não ocupam mais todos os espaços vazios (como no caso $k=2$ ), os indivíduos possuidores de ciclos primos se reproduzem e criam vizinhanças sincronizadas e mais homogêneas, pois na emergência encontram-se muito mais vezes com indivíduos da mesma estratégia do que de outras, e acabam ocupando grandes porções da população, tornando-se as estratégias vencedoras nas amostras.

Nos casos em que $k=4$ (Figura 48) os ciclos primos apresentam também superioridade estratégica, mas não tão destacada quanto nos casos em que $k=3$. Este efeito é explicado pela variação da fração de indivíduos na rede. Nos casos em que $k=3$ a diferença entre a fração inicial e a final é bem maior do 

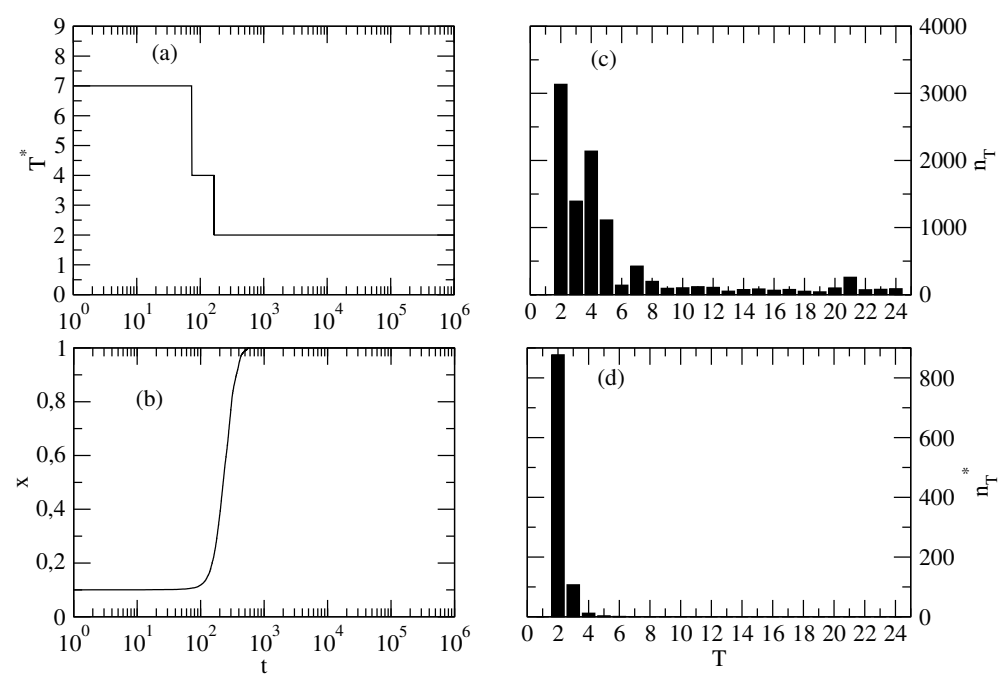

Figura 44: Resultados para $k=2, x_{0}=0.1$ e $\mu=0$

que em $k=4$ o que significa que muito mais indivíduos novos foram criados para ocupar os espaços vazios da rede em $k=3$ de modo que o número de indivíduos com ciclos primos criados tenha sido muito maior. Quando $k=4$ quase não ocorre reprodução na rede, e a que ocorre favorece os primos por causa da alta intensidade competitiva. O histograma das estratégias vencedoras, no entanto, apresenta grandes quantidades de vencedores não primos por causa das flutuações provocadas pelo baixo crescimento populacional.

Em todos os casos em que $\mu=0$ percebemos que a distribuição final de estratégias em uma única amostra apresenta quantidades parecidas de indivíduos em todas as estratégias. Isso ocorre porque como $\mu=0$ toda vez que um indivíduo está ativo numa geração ele morre e é substituído por um descendente de mesma estratégia, o que, no mínimo, conserva o número inicial de indivíduos que possuem cada uma das estratégias. Apenas os indivíduos criados para ocupar os espaços vazios contribuem para alterar a distribuição das estratégias, dando pequena vantagem para alguma das estratégias. Nos casos em que $\mu=10^{-3}$, como podemos notar pela Figura 45 a estratégia vencedora apresenta uma grande vantagem com relação as outras estratégias. 

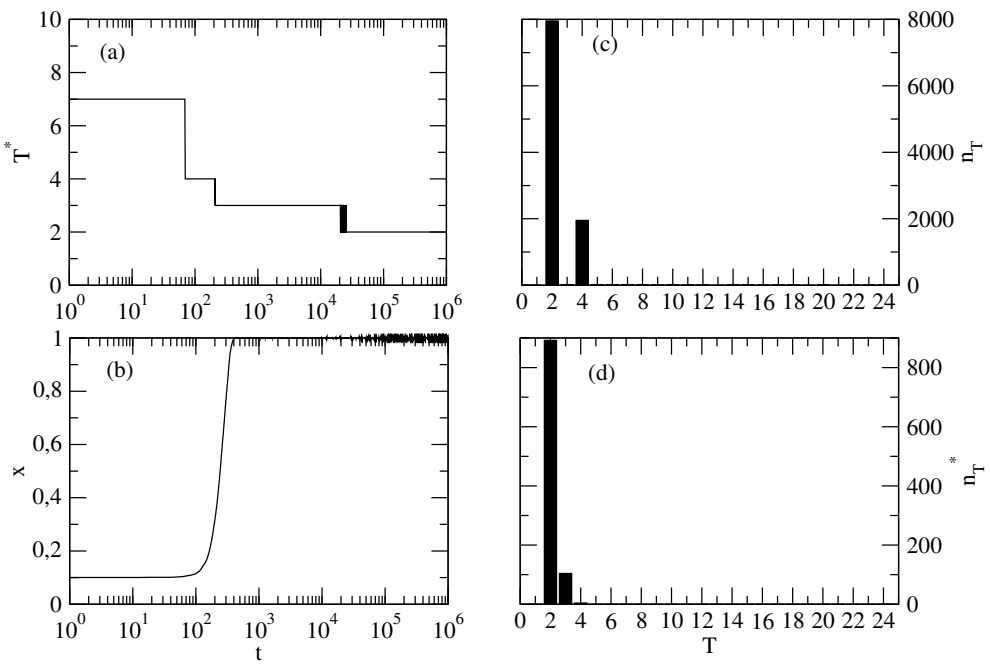

Figura 45: Resultados para $k=2, x_{0}=0.1$ e $\mu=10^{-3}$.
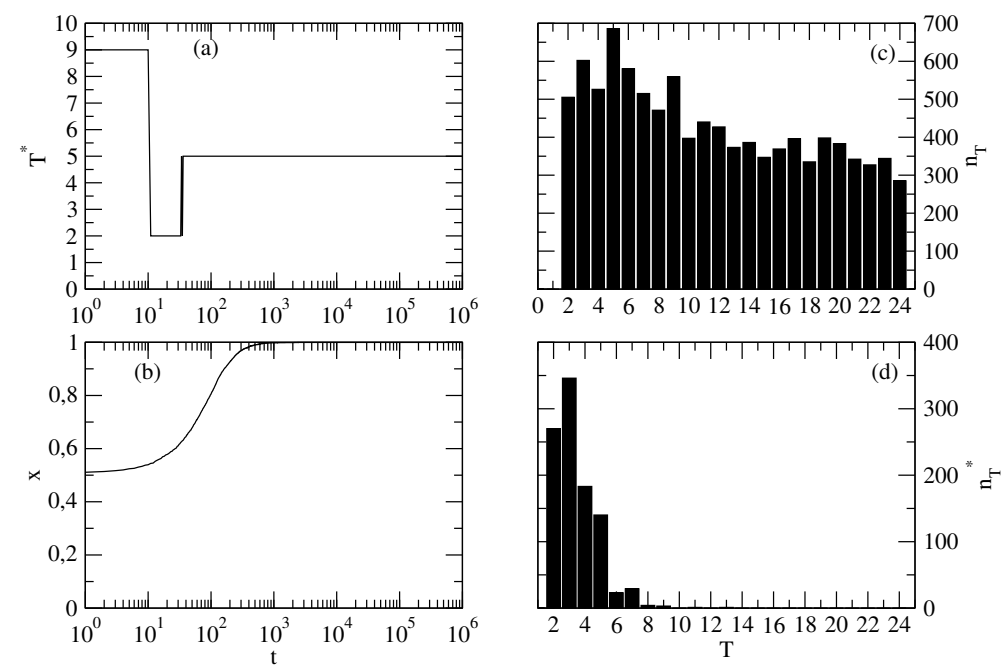

Figura 46: Resultados para $k=2, x_{0}=0.5$ e $\mu=0$. 

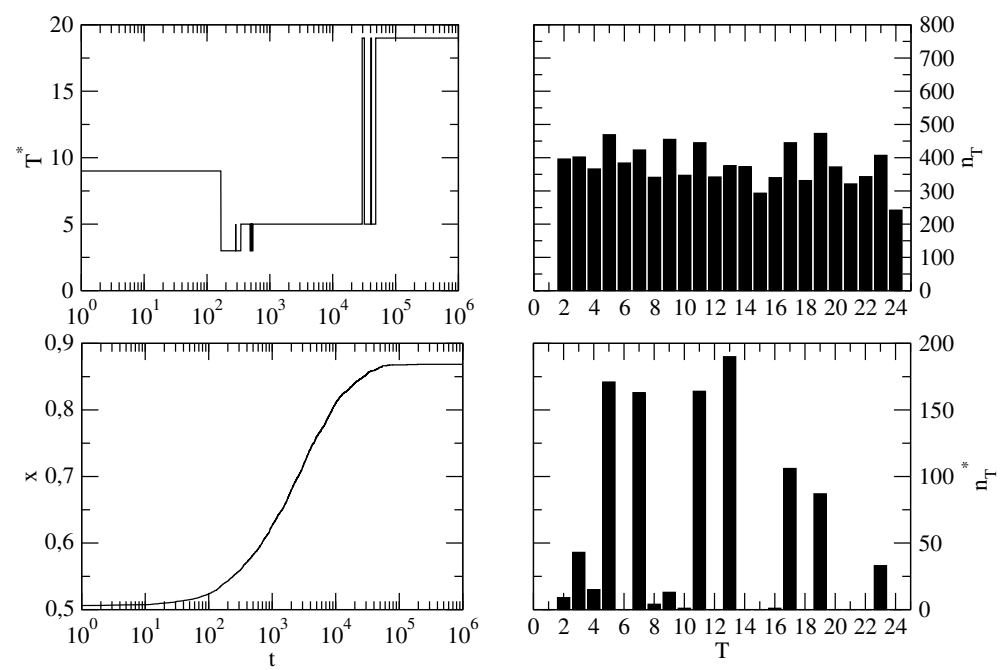

Figura 47: Resultados para $k=3, x_{0}=0.5$ e $\mu=0$.
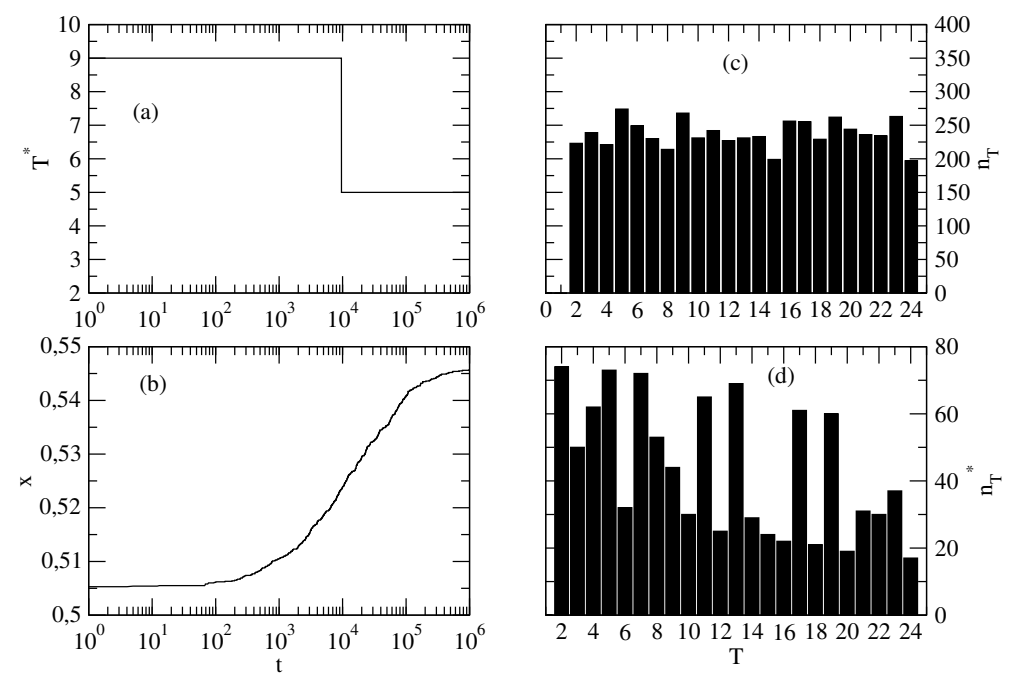

Figura 48: Resultados para $k=4, x_{0}=0.5$ e $\mu=0$. 


\subsection{Conclusão}

Com base nos resultados podemos concluir que as estratégias baseadas em ciclos de vida com duração de números primos de anos podem ser estratégias evolutivamente vencedoras mesmo na ausência de efeitos de predação na população. Também podemos notar que para baixa intensidade de competição existe a predominância de ciclos curtos na população, uma vez que os mesmos ocupam todos os espaços vazios na rede antes que os outros indivíduos possam se encontrar e reproduzir.

Com o aumento da intensidade de competição, através do parâmetro $k$, os primos passam a ter vantagem no crescimento populacional, de modo que quanto maior for este crescimento, maior será a dominância dos ciclos primos como estratégias vencedoras. No entanto o aumento excessivo da intensidade de competição provoca um efeito de paralisação no crescimento da população, uma vez que para haver reprodução seriam necessários muitos indivíduos ativos na mesma vizinhança simultaneamente, de forma que o crescimento populacional fique limitado. Como a dominância dos ciclos primos depende do crescimento da população, num caso onde a intensidade de competição seja relativamente alta, os indivíduos portadores de estratégias primas não conseguirão ocupar todos os espaços vazios da rede, apresentando uma dominância relativamente pequena entre as estratégias vencedoras.

A origem dos ciclos primos, bem como de sua dominância, ainda é

um mistério. É preciso esclarecer quais fatores do modelo são fundamentais para a origem da dominância desses ciclos, como por exemplo a topologia da rede, o formato da vizinhança, a seleção dos grupos, a ausência de mobilidade dos agentes e a própria competição entre as estratégias. Entretanto os resultados aqui apresentados já elucidam que os efeitos de predação não se constituem necessários no processo. 


\section{CONCLUSÕES GERAIS}

Através dos resultados apresentados confirmamos a eficiência do uso dos autômatos celulares em estudos de dinâmica de replicadores em diversas situações distintas, analisando e classificando três modelos que apresentam transições de fase longe do equilíbrio e modelando o comportamento natural de uma espécie de inseto.

No estudo das transições de fase os autômatos celulares nos permitiram, a partir de uma estrutura espacial muito simples, criar um ambiente altamente complexo onde os replicadores evoluíam ou para o estado absorvente, ou para um estado meta estável com propriedades espaciais e temporais muito particulares. No primeiro modelo, replicador-enzima, com dois tipos de agentes em um autômato finito, pudemos identificar um comportamento em lei de potência da probabilidade de sobrevivência estacionária $P(t \rightarrow \infty)$ em relação ao parâmetro de replicação. $\mathrm{O}$ expoente crítico associado a esse comportamento, $\beta^{\prime}$, tornou possível classificar o modelo como pertencente à classe de universalidade da Percolação Dirigida.

No modelo bidimensional de criação por pares e trincas, com o uso de um autômato infinito, realizamos uma análise do espalhamento da população de replicadores ao longo do tempo, e com um autômato finito, simulamos o processo de contato conservativo do modelo. Da análise de espalhamento extraímos os expoentes $\eta, \delta, z$ e $\nu_{\|}$, e do processo de contato conservativo extraímos o expoente $\beta$. A partir do conjunto de expoentes críticos mostramos que o modelo de replicação direta e o de criação por pares pertencem à classe de universalidade da Percolação Dirigida 
enquanto que o modelo de criação por trincas muda de classe de universalidade dependendo da probabilidade individual de replicação, apresentando transição descontínua de fase quando é baixa, passando a ser contínua com o aumento do seu valor, com os expoentes críticos convergindo de forma contínua para os valores correspondentes aos da Percolação Dirigida.

No modelo difusivo de criação por trincas, a partir de um autômato unidimensional infinito realizamos a análise de espalhamento, da qual extraímos os expoentes críticos $\eta, \delta$ e $z$, e de um autômato finito aplicamos o processo de contato conservativo difusivo do qual extraímos o expoente $\beta$. A partir dos expoentes críticos mostramos que existe uma transição no sistema entre as classes de universalidade da Percolação Dirigida e da Percolação Dirigida Compacta à medida que a intensidade de difusão no sistema aumenta.

Na modelagem do comportamento das cigarras do gênero Magicicada pudemos idealizar num autômato celular o comportamento natural dos insetos com relação a um ambiente primitivo essencialmente competitivo e espacialmente estruturado, de onde pudessem surgir as características encontradas na natureza. A dinâmica de replicação neste caso nos mostrou que o efeito competitivo no autômato era suficiente para o surgimento de ciclos de vida com duração de números primos de anos, o que nunca fora feito antes através de um modelo tão simples como o autômato em questão.

Sendo assim, essa pequena amostra do que é possível obter a partir da modelagem da dinâmica de replicadores em redes confirma a grande aplicabilidade do formalismo dos autômatos celulares nos campos da ecologia e da biologia evolutiva, onde outros formalismos por vezes não podem ser aplicados por tornarem os problemas intratáveis. Os autômatos celulares são estruturas muito simples capazes de reproduzir a complexidade dos sistemas reais. 


\section{Bibliografia}

[1] H. Hinrichsen. Advances in Physics, 49(7):815, 2000.

[2] S. Ulam. Sets, Numbers and Universes. MIT, 1974.

[3] J. Von Neumann and O. Morgenstern. Thoery of Games and Economic Behavior. Princeton University Press, 1944.

[4] J. M. Turing. Systems of Logic based on Ordinals. C.F. Hodgson \& Son, 1939.

[5] Stephen Wolfram. Cellular Automata and Complexity. 1994.

[6] H. K. Janssen. Z.Phys. B, 42:151, 1981.

[7] P. Grassberger. Z. Phys. B, 47:365, 1982.

[8] G. Grinstein, Z. W. Lai, and D. A. Browne. Physical Review A, 40:4820, 1989.

[9] R. Dickman and T. Tomé. Physical Review A, 44:4833, 1991.

[10] T. Tomé and M. J. de Oliveira. Nonequilibrium model for the contact process in an ensemble of constant particle number. PRE, 86:5643, 2001.

[11] G. O. Cardozo and J. F. Fontanari. Physica A, 359:478, 2006.

[12] G. O. Cardozo and J. F. Fontanari. The European Physical Journal B, 51:555, 2006. 
[13] M. Lloyd and H. S. Dybas. The periodical cicada problem ii. Evolution, 20:466, 1966.

[14] R. May. Periodical cicadas. Nature, 277:347-349, 1979.

[15] F. C. Hoppensteadt and J. B. Keller. Syncronization of periodical cicada emergences. Science, 194:335, 1976.

[16] K. S. Williams, K.G. Smith, and F.M. Stephen. Emergence of 13-yr periodical cicadas (cicadidae: Magicicada): Phenology, mortality and predator satiation. Ecology, 74(4):1143-1152, 1993.

[17] E. Goles, O. Schulz, and M. Markus. Prime number selection of cycles in a predator-prey model. Complexity, 6:33, 2001.

[18] E. Goles, O. Schulz, and M. Markus. A biological generator of prime numbers. Nonlinear Phenomena in Complex Systems, 3:208, 2000.

[19] A. W. Butler. Bulletin U. S. Dep. Agr. Div. Entomology, 12:24, 1886.

[20] P. R. A. Campos, V. de Oliveira, R. Giro, and D. S. Galv ao. Emergence of prime numbers as a result of evolutionary strategy. Physical Review Letters, 93:098107, 2004.

[21] P. R. Grant. The priming of periodical cicada life cycles. Trends in Ecology and Evolution, 20:169, 2005.

[22] R.T. Cox and C.E. Carlton. Paleoclimatic influences in evolution of periodical cicadas. Am. Midl. Nat., 120:183-193, 1988.

[23] R.T. Cox and C.E. Carlton. Evidences of genetic dominance of 13-year life cycle in periodical cicada. Am. Midl. Nat., 125:63-74, 1991.

[24] R.T. Cox and C.E. Carlton. A commentary on prime numbers and life cycles of periodical cicadas. American Naturalist, 152:162-164, 1998. 
[25] J. Yoshimura. The evolutionary origins of periodical cicadas during ice ages. American Naturalist, 149:112-124, 1997.

[26] K.S. Williams and C. Simon. The ecology behavior, and evolution of periodical cicadas. Annual Review of Entomology, 40:269-295, 1995.

[27] C. Simon et. al. Genetic evidence for assortative mating between 13-year cicadas and sympatric 17-year cicadas with 13-year life cicles provides support for allochronic speciation. Evolution, 54:1326-1336, 2000.

[28] D. Mollison. Journal of Royal Statistical Society, B39:283, 1977.

[29] E. V. Albano. Journal of Physics A, 27:L881, 1994.

[30] S. Havlin and D. Ben Avraham. Advances in Physics, 36:695, 1987.

[31] J. P. Bochaud and A. Georges. Physics Reports, 195:127, 1990.

[32] J. W. Essam. Rep. Prog. Phys., 43:833, 1980.

[33] D. Stauffer and A. Aharony. Introduction to Percolation Theory. Taylor \& Francis, 1992.

[34] S. R. Broadbent and J. M. Hammersley. Proc. Camb. Phyl. Soc., 53, 1957.

[35] T. E. Harris. Ann. Prob., 2:969, 1974.

[36] W. Kinzel. Z. Phys. B, 58:229, 1985.

[37] J. W. Essam. Journal of Physics A, 22:4927, 1989.

[38] J. F. F. Mendes, R. Dickman, and H. Herrman. Physical Review E, 54:3071, 1996.

[39] R. Dickman and I. Jensen. Physical Review Letters, 67:2391, 1991.

[40] R. Dickman and I. Jensen. Journal of Statistical Physics, 71:89, 1993. 
[41] R. Dickman and J. K. da Silva. Physical Review E, 58:4266, 1998.

[42] Joaquín Marro and Ronald Dickman. Nonequilibrium Phase Transitions in Lattice Models. Cambridge University Press, 1999.

[43] T.M. Liggett. Interacting Particle Systems. Springer Verlag, 1985.

[44] N. Konno. Phase Transitions of Interacting Particle Systems. World Scientific, 1994.

[45] L. D. Landau and E. M. Lifshitz. Statistical Mechanics. Pergamon Press, 1958.

[46] D. Ruelle. Statistical Mechanics: Rigorous Results. Benjamin,Reading, 1969.

[47] R. B. Griffiths. Phase Transitions and Critical Phenomena, volume 1. Academic Press, 1972.

[48] R. M. Ziff and B. J. Brosilow. Physical Review A, 46:4630, 1992.

[49] R. M. Ziff, E. Gulari, and Y. Barshad. Physical Review Letters, 56:2553, 1986.

[50] R. Dickman, I. Jensen, and H. C. Fogedby. Physical Review A, 41:3411, 1990.

[51] C. A. Voigt and R. M. Ziff. Physical Review E, 56:6241, 1997.

[52] T. Aukrust, D. A. Browne, and I. Webman. Physical Review A, 41:5294, 1990.

[53] T. Tomé and M. J. Oliveira. Dinâmica estocástica e irreversibilidade. Edusp, 2001.

[54] H. Hinrichsen. cond-mat/0006212.

[55] C. E. Fiore and M. J. de Oliveira. Physical Review E, 70:046131, 2004.

[56] R. H. Beamer. Studies on the biology of kansas cicadæ. The University of Kansas Science Bulletin, 18:155, 1928.

[57] S. Wright. Evolution in mendelian populations. Genetics, 16:97, 1931. 
[58] C. L. Marlatt. The periodical cicada. U. S. D. A. Bureau of Entomology Bulletin, $71: 1,1907$.

[59] R. Karban, C.A. Black, and S.A. Weinbaum. How 17-year cicadas keep track of time. Ecology Letters, 3:253-256, 2000.

[60] H. Behncke. Periodical cicadas. Journal of Mathematical Biology, 40:413-431, 2000.

[61] G.F. Webb. The prime number periodical cicada problem. Discrete and Continuous Dynamical Systems - Series B, 1(3):387-399, 2001.

[62] C. Symon and A. Martin. Periodical cicadas. Nature, 341:288, 1989.

[63] R. Karban. Periodical cicada nymphs impose periodical oak tree wood accumulation. Nature, 287:326, 1980.

[64] M.G. Ritchie. Chronic speciation in periodical cicadas. Trends in Ecology and Evolution, 16(2):59-61, 2001. 